\title{
Chromosome tangling and breakage at anaphase result from mutations in lodestar, a Drosophila gene encoding a putative nucleoside triphosphate- binding protein
}

\author{
Charles H. Girdham and David M. Glover \\ Cancer Research Campaign Cell Cycle Genetics Group, Department of Biochemistry, Medical Sciences Institute, \\ The University, Dundee DD1 4HN, Scotland
}

\begin{abstract}
We describe a Drosophila maternal-effect gene, lodestar, mutations in which cause chromatin bridges at anaphase. lodestar maps to cytological position 84D13-14, and we identified the lodestar gene in germ-line transformation experiments by the ability of a genomic fragment to restore fertility to females homozygous for lodestar mutations. lodestar encodes a potential nucleoside triphosphate binding protein, which is a novel member of the D-E-A-H box family of proteins. Antibodies raised against the lodestar gene product detect a protein that undergoes cell cycle-dependent changes in distribution in the embryo. The protein is cytoplasmic at interphase, and rapidly enters the nucleus early in prophase. It is restricted to the region enclosed by the spindle envelope during metaphase and anaphase; but by telophase, the lodestar protein is contained entirely within the reforming nucleus.
\end{abstract}

[Key Words: Cell division; Drosophila maternal-effect mutation; Drosophila embryogenesis; NTP-binding protein]

Received July 1, 1991; revised version accepted August 15, 1991.

The biology of Drosophila offers an opportunity for directing a molecular genetic approach to the dissection of cell division. There are two major stages of the Drosophila life cycle at which mutations in genes involved in mitosis may cause lethality: during early embryogenesis and at the larval-pupal boundary. The Drosophila embryo undergoes 13 rapid rounds of synchronous nuclear division as a syncytium before the nuclei are budded off into cells by the down-growth of the blastoderm membrane (Foe and Alberts 1983) to form a cellular blastoderm of $\sim 5000$ cells $\sim 2.5 \mathrm{hr}$ after egg deposition. The syncytial nuclear cycles are entirely dependent on transcripts (and proteins) deposited in the oocyte during oogenesis (Edgar and Schubiger 1986), and mutations in genes required during this period can exert a strong maternal effect. After formation of the cellular blastoderm, mitosis becomes dependent on transcription of the zygotic genome, which begins at a high level at cycle 14 (Edgar and Schubiger 1986). Edgar and O'Farrell (1989, 1990) have shown that expression of the string gene, which encodes the Drosophila homolog of the Schizosaccharomyces pombe cdc25 protein, is rate-limiting for mitosis of cycle 14 land probably later embryonic cycles). Cell division arrests after cellularization in string mutants, which show some of the earliest pheno- types of a zygotic lethal mutation. This agrees with observations that deficiencies in the zygotic genome do not prevent completion of the syncytial nuclear cycles and cause defects that are first detectable at the time of cellularization (Merrill et al. 1988; Wieschaus and Sweeton 1988). The maternal transcripts and proteins of other genes required for cell division can be sufficient to allow the organism to complete embryonic development /Garcia-Bellido and Moscoso del Prado 1979; Szabad and Bryant 1982; Gatti et al. 1983; Gatti and Baker 1989|. Products involved in cell division are utilized during the larval period for the expansion of the populations of imaginal cells that will form the structures of the adult. However, these imaginal cells are entirely dispensable for larval development (Shearn et al. 1971; Szabad and Bryant 1982), which occurs via cell growth and chromosome polytenization rather than cell division. The failure to expand the imaginal cell populations during larval development becomes lethal at the larval-pupal boundary, when the larval cells degenerate. Examination of dividing neuroblasts in the late larval period indicates that a significant proportion of mutations causing lethality at this stage are likely to be in genes encoding functions involved in cell division (e.g., Gatti et al. 1983; Smith et al. 1985; Gatti and Baker 1989). 
Drosophila mutation causing anaphase bridges

The organization of the nuclear cycles during the syncytial period differs from that of the cell cycles after cellularization (Cross et al. 1989; for review, see O'Farrell et al. 1989|. The syncytial nuclear cycles consist entirely of $S$ phases followed by $M$ phases with no discernible gap periods. The first $G_{2}$ period occurs in cycle 14 during which the syncytial blastoderm becomes cellularized (Edgar and O'Farrell 1989). Overall synchrony of cycling is lost at this stage, and groups or domains of cells enter mitosis of cycle 14 together in a complex but reproducible, pattern, after $G_{2}$ periods varying from 30 to $150 \mathrm{~min}$ (Foe 1989). The syncytial cycles are also characterized by fewer controls linking the completion of early cycle events to the initiation of later events (for review, see Hartwell and Weinert 1989). Thus, during the syncytial period, the inhibition of DNA synthesis with aphidicolin does not prevent entry into mitosis (Raff and Glover 1988). The distinctive features of the embryonic cycles, such as their rapidity and lack of feedback control points, may require the activity of a special set of gene products. Mutations in this group of genes would be expected to have a strict maternal effect with no zygotic lethality. Only a few genes identified so far have these characteristics. The $f_{s}(1) Y a$ gene is a strict maternal-effect locus encoding a cell cycle-dependent nuclear envelope component (Lin and Wolfner 1991). Similarly, the abnormal chromatin gene is required only for nuclear cycles in the syncytial embryo; no mitotic abnormalities are observed in larval neuroblasts (Vessey et al. 1991). The giant nuclei gene may also define a strict maternal locus required for the suppression of DNA replication in the unfertilized egg (Freeman et al. 1986; Freeman and Glover 1987).

We describe a gene, lodestar, that exerts a strong maternal effect and is essential for embryonic mitoses. Mutations at the lodestar gene also have a weak zygotic phenotype of defective mitosis during larval development, but the function seems to be redundant in the zygote. Mutation at the lodestar gene causes a phenotype of chromatin bridging at anaphase. We have cloned the lodestar gene and show that the gene product is a putative nucleoside triphosphate (NTP)-binding protein that undergoes a novel cell cycle-dependent redistribution between the cytoplasm and the nucleus.

\section{Results \\ lodestar mutations cause chromatin bridging at mitosis}

We have screened collections of female sterile and maternal-effect lethal mutations looking for defective mitosis in the syncytial embryo and have identified the lodestar gene as a candidate for a gene involved in cell division on the basis of the abnormal appearance of chromatin in embryos from homozygous lodestar females. There are four mutant alleles of the lodestar gene $\left(1 d s^{042-13}, 1 d s^{098-1}, 1 d s^{298-8}\right.$, and $\left.1 d s^{352-16}\right)$, all induced by ethylmethane sulfonate and isolated from a collection of mutations made in Tübingen [Tearle and Nüsslein-Volhard (1987); in an independent screening of this collection of mutations, by analysis of larval neuroblast squashes, M. Gatti (pers. comm.) has also identified lodestar as a mitotic mutant]. Females homozygous for each of these mutations produce embryos that die early in embryogenesis (embryos produced from females lacking a wild-type copy of the lodestar gene will be referred to as LDS embryos). No LDS embryos have ever been observed to hatch, indicating that the maternal-effect phenotype is $100 \%$ penetrant and that these mutations are not subject to paternal rescue.

LDS embryos show defects in nuclear division that become apparent during the syncytial period. All of the alleles show some variability in phenotype (Fig. 1). Some LDS embryos fail to develop beyond the syncytial stages and show defective nuclei in the interior of the embryo prior to nuclear migration at cycle 9 (Fig. 1D). Some show blastoderm defects (Fig. 1E-G), whereas others can undergo morphogenetic movements characteristic of gastrulation (Fig. $1 \mathrm{H}, \mathrm{I}$ ), but always show severe defects in cell division patterns and the structure of the cell layers. Development can proceed to this stage in embryos from hemizygous mothers, in which the lodestar alleles are placed over a deficiency for the region [Df(3R)dsx21; see below]. The continuation of morphogenetic events despite abnormal cell numbers is not unprecedented. Embryos homozygous for mutations at the string gene cellularize after cycle 13 but fail to undergo any further rounds of mitosis. In spite of this, the events
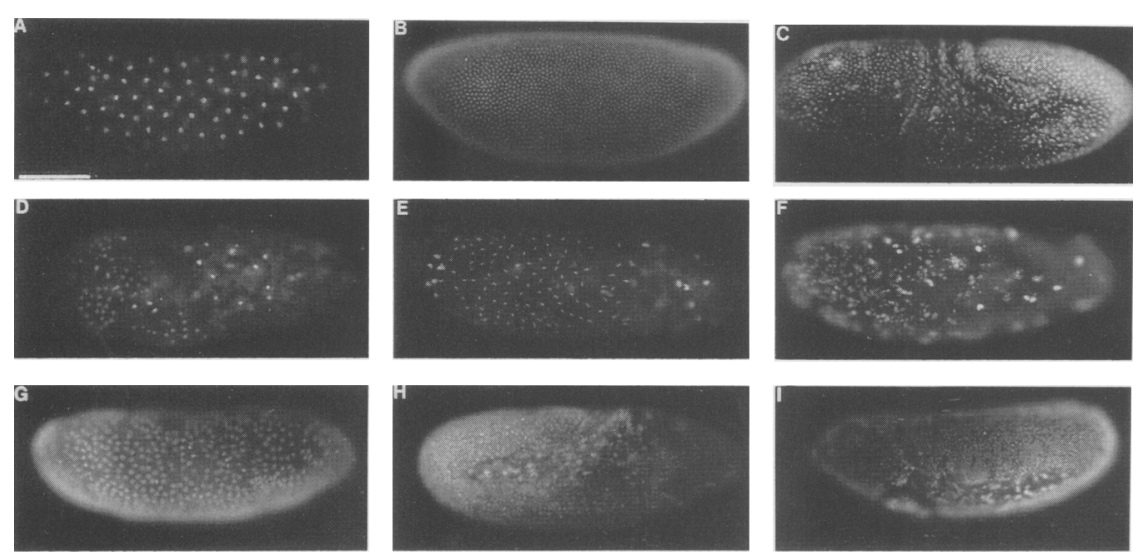

Figure 1. LDS embryos are heterogeneous in their extents of development. Wild-type $(A-C)$ and LDS $(D-I)$ embryos were stained with Hoechst 33258 to reveal DNA. The wild-type embryos are at the following stages: $(A)$ prophase of nuclear cycle $10,(B)$ interphase of cycle 14 ; $(C)$ gastrulation with several domains of cells entering mitosis of cycle 14. The LDS embryos $(D-G)$ show dramatically uneven distributions of nuclei at the surface of the syncytial blastoderm and lack of cycle synchrony. LDS embryos in $H$ and $I$ appear to have undergone at least partial cellularization and have cell numbers characteristic of cycles 15 and 16 . Bar, $100 \mu \mathrm{m}$. 
of gastrulation take place with approximately normal timing in string ${ }^{-}$embryos (Edgar and O'Farrell 1989). Gastrulation has also been observed in embryos showing abnormal mitosis as a result of mutations in the abnormal spindle gene in their mothers (Gonzalez et al. 1990).

The most obvious defect in LDS embryos is the uneven nuclear density observed at the surface of the syncytial blastoderm at cycle 10 after nuclear migration (Fig. $1 \mathrm{E}-\mathrm{G})$. Nuclei corresponding to the gaps in the layer can be observed just below the plane of the monolayer, as if they have failed to migrate to the surface or have subsequently fallen below it. These regions of the cortex devoid of nuclei still often contain centrosomes nucleating asters of microtubules (not shown). These "extra" centrosomes would appear to have become dissociated from their nuclei, and we assume that they are undergoing cycles of division. The uncoupling of centrosome replication from nuclear replication during the Drosophila syncytial cycles has been demonstrated previously by using the DNA polymerase inhibitor aphidicolin (Raff and Glover 1988, 1989) and has been observed in other mitotic mutants such as giant nuclei (Freeman et al. 1986), abnormal spindle (Gonzalez et al. 1990), abnormal chromatin (Vessey et al. 1991), and quartet (Zahner and Cheney 1990).

The phenotype that is characteristic of LDS embryos is a failure to separate chromatin at anaphase (Fig. 2). Anaphase figures in LDS embryos are often tangled with chromatin remaining at the metaphase plate (Fig. 2C,D). Chromatin can decondense in the absence of complete chromatid segregation, and midbody formation initiates over the bridging chromatin (Fig. 2E,F). This failure to separate chromatin during mitosis can also result in chromatin fragmentation, and chromatin fragments remaining between telophase nuclei are observed (Fig. $2 \mathrm{H}$ ). The phenotype of chromatin bridging at anaphase has been identified in the embryos of mothers both homoand hemizygous for all the lodestar alleles and in two trans-heterozygous combinations that have been examined $\left(1 d s^{352-16} / 1 d s^{298-8}\right.$ and $\left.1 d s^{042-13} / 1 d s^{098-1}\right)$. The phenotype is seen in both syncytial and cellularized embryos. The structure of the spindle of bridged anaphase figures appears to be normal, but nuclei in LDS embryos also show multipolar and branched spindle structures with hyperploid chromosome complements (not shown). Such spindle structures have been observed in mutants of other genes involved in mitosis (C.H. Girdham and D.M. Glover, unpubl.).

We have also examined cell division in larval neuroblasts from animals homozygous for lodestar mutations and find similar phenotypes to those observed during the embryonic cycles (Fig. 2J,K).

\section{Mapping and cloning of the lodestar gene}

We mapped the lodestar mutation by standard recombination techniques (see Materials and methods) to genetic map position $3-47.8$ on the third chromosome. Subsequent cytological mapping allowed lodestar to be posi- tioned in a very small interval at $84 \mathrm{D} 13-14$, delimited by the distal breakpoints of the $\mathrm{Df}(3 \mathrm{R})$ Antp17 and $\mathrm{Df}(3 \mathrm{R})$ ds $2 M$ deficiency chromosomes, which are indistinguishable at the level of polytene chromosome cytology (Lindsley and Zimm 1987; C.H. Girdham and D.M. Glover, unpubl.). The lodestar mutation does not lie within the region of the Antp17 deletion, as lodestar/ Df(3R)Antp17 females are fertile, but does lie in the $d s \times 2 M$ deletion, as lodestar/Df(3R)dsx2M females are sterile.

This entire region defined to contain the lodestar gene has been cloned in a chromosome walk carried out to isolate the doublesex gene (Baker and Wolfner 1988). In this work, Baker and Wolfner mapped the distal breakpoints of the Df(3R)Antp17 and $\mathrm{Df}(3 \mathrm{R}) d s \times 2 M$ deficiency chromosomes at the molecular level and showed that they were separated by $30 \mathrm{~kb}$ (Fig. 3). The doublesex gene extends $15 \mathrm{~kb}$ into this interval. Preliminary analysis of transcripts by Northern blotting carried out by us and by B.S. Baker and M.F. Wolfner (unpubl.) using cloned DNA from the interval indicated that there were likely to be at least four different genes in the remaining $15 \mathrm{~kb}$ of the region. We used DNA probes from the interval to isolate cDNA clones from an early embryonic library (Brown and Kafatos 1988). Southern blotting and restriction enzyme cleavage mapping allowed the transcribed regions to be positioned accurately on the molecular map of the region. We then undertook to introduce the two genomic DNA fragments indicated in Figure 3 into flies by P-element-mediated germ-line transformation (see Materials and methods). These two fragments contain genes expressed at elevated levels in adult females and early embryos and were considered to represent the two best candidates for the lodestar gene. One of the two fragments (labeled pW8A in Fig. 3) was found to restore fertility to females homozygous for lodestar mutations, indicating that it contained the lodestar transcription unit.

The lodestar transcript is present throughout development and overlaps with the $3^{\prime}$ end of the doublesex transcript

The lodestar gene produces a major transcript of $3.5 \mathrm{~kb}$ that is present throughout development, but at greatly elevated levels in the adult female and the early embryo (Fig. 4A). A minor transcript of $3.8 \mathrm{~kb}$, which is likely to be produced by use of an alternative polyadenylation signal (see below), is also visible in the adult female and early embryo tracks. No transcripts are detected in females lacking ovaries through the effects of gonadal dysgenesis, indicating that the transcript is ovary specific in the adult female (Fig. 4C). The maternal transcript deposited in the oocyte during oogenesis is degraded during the syncytial period of development, and little transcript remains at the time of cellularization of the blastoderm (data not shown). These features of the transcription unit are consistent with this being a gene with a strong maternal effect.

We isolated two classes of lodestar cDNA clones from a 0- to 4-hr embryo cDNA library (Brown and Kafatos 

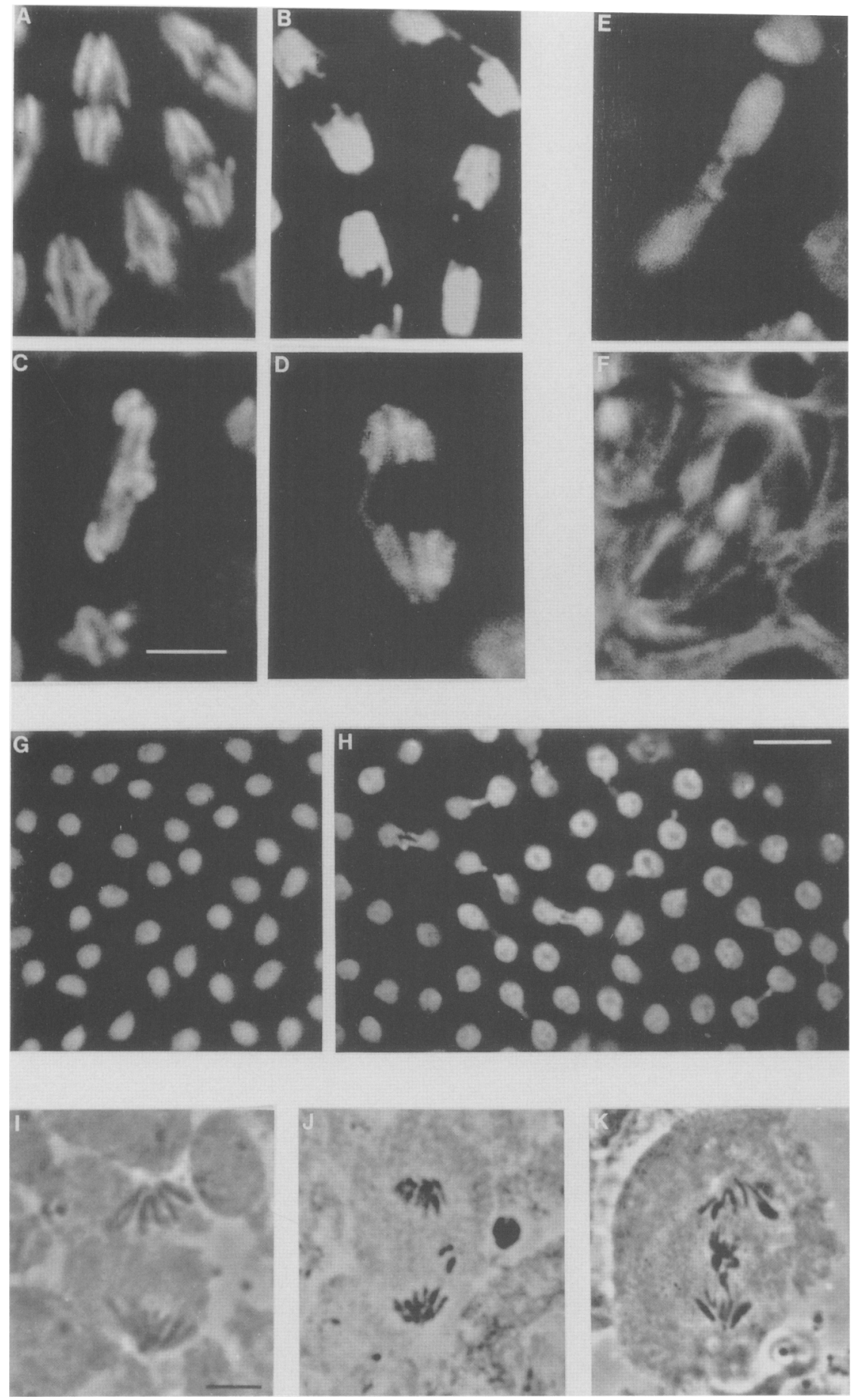

Figure 2. lodestar mutations result in chromatin bridging at anaphase. $(A-E)$ DNA stained with propidium iodide. $A$ and $B$ are fields taken from wild-type embryos. $(A)$ Early anaphase $A ;(B)$ anaphase B. $C$ and $D$ are anaphase figures from LDS embryos showing chromatin bridging. $(C)$ An anaphase figure with a mass of chromatin remaining at the metaphase plate; $(D)$ an anaphase B-like mitotic figure with a connection between a single pair of chromatid arms. $(E)$ Telophase figure from a cellularized LDS embryo. $(F)$ Corresponding field stained with an antibody against tubulin apparently indicating the formation of a mid-body over the region of connecting chromatin. Bar, $5 \mu \mathrm{m},(A-F) .(G, H)$ Fields from syncytial embryos at telophase stained with propidium iodide to reveal DNA. $(G)$ Wild-type embryo; $(H)$ LDS embryo. Many of the pairs of telophase nuclei in $H$ are connected by threads of chromatin or show fibers of chromatin extending along the axis of the spindle which have not been absorbed into the telophase nucleus. Bar, $10 \mu \mathrm{m}$. $(I-K)$ Preparations of squashed larval neuroblasts stained with aceto-orcein to reveal chromatin. (I) Anaphase figure from a wild-type larva; $(J, K)$ anaphase figures from larvae homozygous for lodestar mutations. / shows two fragments of chromatin lying in the midregion of the spindle; $K$ shows a mass of chromatin remaining at the position of the metaphase plate and is comparable to the figure taken from a LDS embryo shown in C. Bar, $5 \mu \mathrm{m}$.
1988) distinguishable by the presence of an EcoRI restriction enzyme site and 300 bases of additional sequence at the $3^{\prime}$ end of the clone. These two types of cDNA are likely to represent the two lodestar transcripts identified on Northern blots. We have sequenced the $3^{\prime}$ ends of several of the lodestar cDNA clones and find them to be complementary to sequence obtained for the $3^{\prime}$ end of the male-specific doublesex transcript (Burtis and Baker
1989). The largest of the lodestar cDNA clones overlaps with doublesex by $>550$ bp (Fig. 3).

\section{Sequence of the lodestar $c D N A$}

The sequence of the largest lodestar cDNA is presented in Figure 5. The proposed initiation codon (at position 85 in the sequence) lies in the context AAAAATG, which is 
centromere

Df(3R)dsx2M

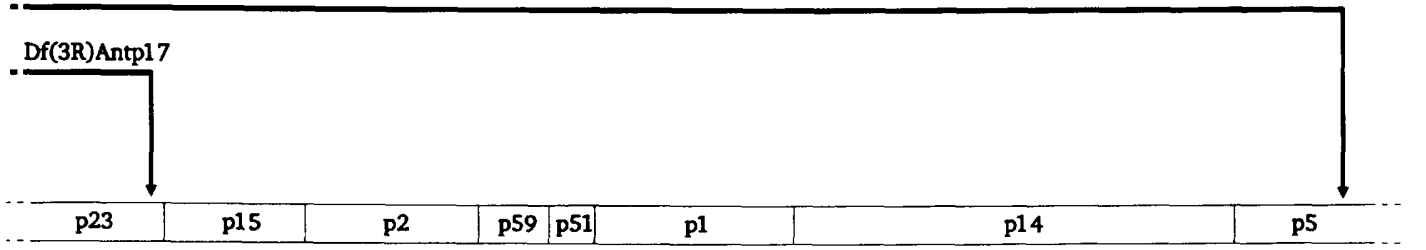

genomic DNA

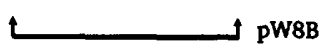

PWBA

fragments for transformation
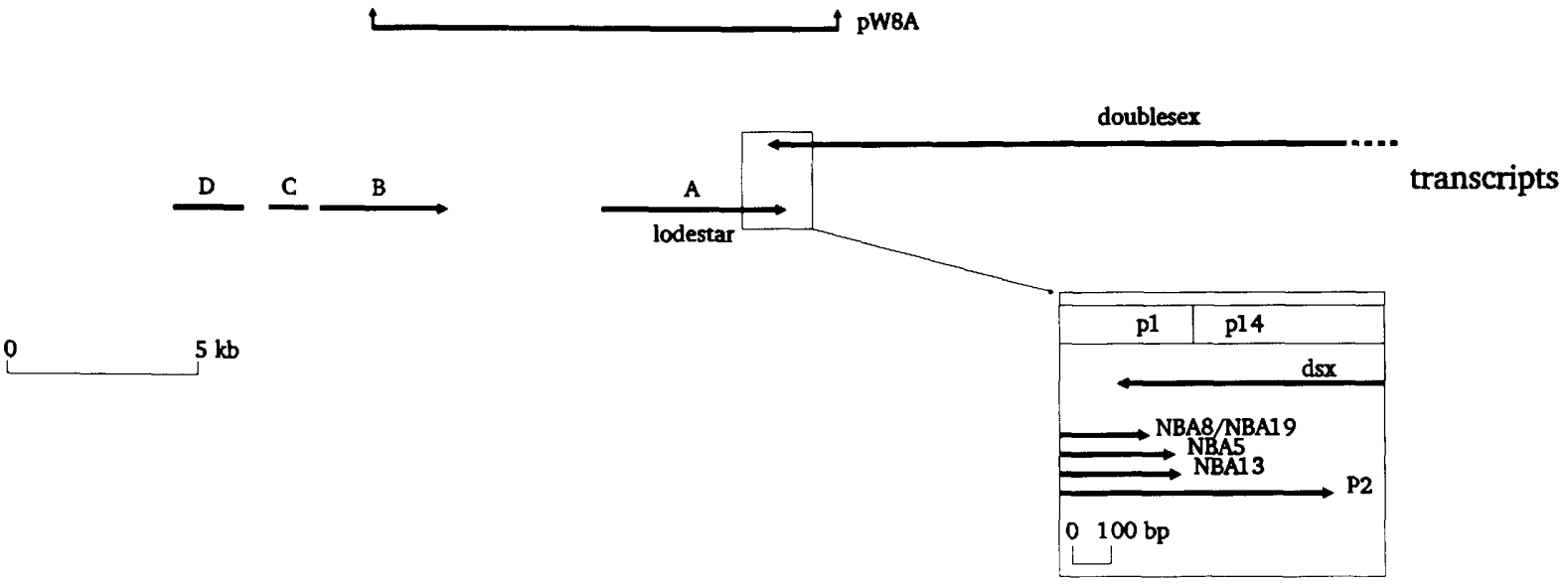

Figure 3. Mapping and cloning of the lodestar gene. Shown is the position of the lodestar gene between the distal breakpoints of the deficiency chromosomes Df(3R)Antp17 and Df(3R)dsx2M (indicated with arrows). The bars show the positions of the EcoRI sites in the interval. The designation of each fragment is as in Baker and Wolfner (1988). pW8A and pW8B are fragments of genomic DNA that were inserted into the $\mathrm{pW} 8$ vector (Klemenz et al. 1987) and were introduced into flies using P-element-mediated germ-line transformation. Transcripts $A-D$, identified in the interval, are shown below, with the directions of transcription (where known). The presence of the genomic DNA fragment from pW8A in the mother rescues LDS embryos, indicating that transcription unit A is the lodestar gene. The box shows an enlargement of the region where the doublesex and lodestar genes overlap. The arrowheads mark the $3^{\prime}$ ends of five lodestar cDNA clones that overlap with the final male-specific exon of the doublesex gene (Burtis and Baker 1989). All of the lodestar cDNAs sequenced are likely to have complete $3^{\prime}$ ends, as consensus sequences required for $3^{\prime}$-end formation (Birnstiel et al. 1985) could be identified for each clone.

an excellent match to the consensus Drosophila melanogaster initiation codon derived by Cavener (1987): C/A AA A/C ATG. There are stop codons in all three reading frames upstream of this sequence. This, together with the identification of consensus polyadenylation signals, suggests that the lodestar cDNAs analyzed incorporate the entire coding region. We have not determined the transcription start site of the lodestar gene, but the length of the sequence obtained is in close agreement with the predicted size of the transcript derived from Northern hybridization.

The putative lodestar protein sequence can be divided loosely into three domains: the amino-terminal 300 amino acids are strongly acidic and contain $27 \%$ serine/ threonine residues; the central portion of the protein shows alternating hydrophobic and hydrophilic regions, possibly indicative of a globular domain; the carboxyterminal 100 amino acids contain an increased proportion of hydrophobic relative to charged residues. The pu- tative protein shows no strong homology to other proteins in computer-held data bases, but we note several motifs in the product. There are sequences that are homologous to those identified in a range of proteins with NTP-binding sites. The homology to any particular member of the family of NTP-binding proteins is not strong, but the occurrence of both the A and B NTPbinding boxes (Walker et al. 1982) at an appropriate spacing led us to identify this homology. The sequence of the B box (IILDEAH) is similar to that of the D-E-A-H family of ATP-dependent helicase proteins /Gorbalenya et al. 1989|, which include translation initiation factors, proteins involved in RNA splicing, and DNA repair proteins. Sequences corresponding to conserved motifs I, Ia, II, and III (Gorbalenya et al. 1989) which are likely to be involved in binding the NTP molecule, can be identified in the putative lodestar sequence (boxed in Fig. 5). Motifs I and II are most important for NTP binding and correspond to the A and B boxes identified previously 


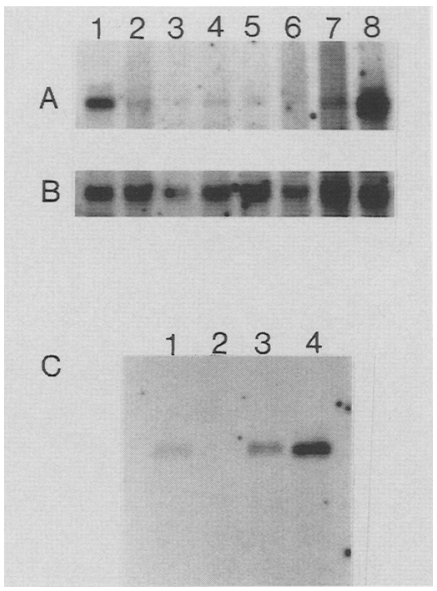

Figure 4. Transcription of the lodestar gene. $(A)$ poly $(A)^{+}$RNA isolated from developmentally staged animals was probed with a double-stranded probe made from a lodestar cDNA clone. The major transcript is $3.5 \mathrm{~kb}$; a minor transcript, most clearly visible in the early embryo (lane 1) and adult female (lane 8), is 3.8 $\mathrm{kb} .(B)$ The same blot hybridized with a Dmras probe (Mozer et al. 1985), which recognizes a nondevelopmentally regulated transcript of $1.6 \mathrm{~kb}$ and indicates approximately even loading of the lanes. (Lane 1) 0- to 4-hr embryos; (lane 2) 4- to 22-hr embryos; (lane 3) first-instar larvae; (lane 4) second-instar larvae; (lane 5) third-instar larvae; (lane 6) pupae; (lane 7) adult males; (lane 8$)$ adult females. $(C)$ poly $(\mathrm{A})^{+}$RNA isolated from adult males and females, which were the progeny of a strongly P-M dysgenic cross ( $\mathrm{P}$, males; $M$ females) and had rudimentary gonads, together with RNA isolated from the progeny of the reciprocal nondysgenic cross (M, males; $P$, females) as a control, was hybridized with a lodestar cDNA probe as in $A$. (Lanes 1,2$)$ Males and females, respectively, from the dysgenic cross; (lanes $3,4)$ males and females, respectively, from the reciprocal nondysgenic cross. lodestar transcripts are absent from females lacking ovaries through gonadal dysgenesis (lane 2) and are present at a reduced level in males from the same cross (lane 1).

(Walker et al. 1982). lodestar sequences equivalent to motifs Ia and III are quite highly diverged from those of the helicase superfamilies. The absence of sequences corresponding to motifs IV, V, and VI, which are thought to be involved in nucleic acid-binding and helicase activity, indicates that the function of NTP binding, and presumably NTP hydrolysis, by the lodestar protein is unclear. The lodestar protein may define a new family of proteins related to the helicase superfamily.

The lodestar sequence also contains a string of basic amino acids (KNKKRK) that we suggest may function as a nuclear localization signal (NLS) in the context of the protein distribution described below. Although a precise consensus sequence for NLSs has yet to be defined, those identified so far consist of a short sequence of predominantly basic residues (Kalderon et al. 1984; for review, see Roberts 1989). Recently, it has been noted that potential casein kinase II (CK II) phosphorylation sites are located close (within 10-30 residues) to many NLS sequences, and it is speculated that phosphorylation of these sites by CK II may modulate rates of nuclear protein transport (Rihs et al. 1991). Potential CK II sites can be identified close to the putative lodestar NLS: DESSDSDSEDDKNKKRK /serine residues that may be targets for CK II are italicized). We also note that the lodestar sequence has four potential PEST regions, which are characteristic of unstable proteins with rapid rates of intracellular turnover (Rogers et al. 1986; Rechsteiner 1988; see legend to Fig. 5).

\section{The lodestar protein undergoes cell cycle-dependent changes in distribution}

To examine the distribution of the lodestar protein in Drosophila embryos, we prepared antisera against a lodestar/B-galactosidase fusion protein synthesised in Escherichia coli. We inserted a $2.6-\mathrm{kb}$ portion of the lodestar cDNA into the pUR291 vector (Ruther and Muller-Hill 1983 ) to create an in-frame lacZ/lodestar fusion. This portion of the cDNA contains $>90 \%$ of the lodestar open reading frame, incorporating amino acids 36-924. The chimeric lacZ/lodestar gene was expressed in Escherichia coli, and the $210-\mathrm{kD}$ fusion protein was purified by gel filtration (see Materials and methods) and used to raise antisera in rabbits. The rabbit antiserum was affinity purified against a column of agarose beads carrying covalently linked fusion protein and is specific for a 155$\mathrm{kD}$ protein that is present in extracts made from early embryos (Fig. 6, lane 1). In adult females this $155-\mathrm{kD}$ protein is only found in the ovary (lane 3 ), consistent with the identification of an ovary-specific lodestar transcript. When a blot of protein prepared from ovaries of adult females hemizygous for each of the lodestar alleles was probed with the lodestar antiserum, we failed to detect any 155-kD protein in the $1 d s^{098-1}$ and $1 d s^{298-8}$ alleles (lanes 6,7). The $1 d s^{042-13}$ allele made a protein slightly smaller than $155 \mathrm{kD}$ (lane 4) and the $1 d s^{352-16}$ allele produced a protein of apparently wild-type size (lane 5).

We used the anti-lodestar antiserum to determine the distribution of the lodestar protein in fixed preparations of early Drosophila embryos. The lodestar protein is located in the cytoplasm during interphase but rapidly redistributes into the nucleus shortly after the entry into mitosis (Fig. 7). The protein enters the nucleus early in prophase just after chromosome condensation has begun. The speed with which the protein enters the nucleus is striking. Nuclear division in the syncytial Drosophila embryo is not precisely synchronous, and mitosis occurs in waves with the nuclei at the poles dividing before those at the equator. Foe and Alberts (1983) estimated that these waves took $\sim 30$ seconds to traverse the embryo. We estimate that the lodestar protein takes $<5 \mathrm{sec}$ to achieve full redistribution from the cytoplasm to the nucleus. There are few nuclei at intermediate stages in the redistribution process in Figure 7B. Examination of prophase nuclei containing condensing chromatin at high magnification indicates that there is no obvious association of the lodestar protein with chromatin (Fig. 7D).

As the chromosomes align on the metaphase plate the lodestar protein assumes a diamond shape with its long 
. M S S E N 作 $\begin{array}{lllllllllllllllllllllllllllllllllll}6 & S & E & Y & Y & S & D & K & E & E & D & S & V & V & N & N & S & S & L & G & R & S & R & K & S & S & R & L & S & K & S & S & R & L\end{array}$ 199 AGCAAATCCTCGCGCCCCAGCAGCGCTGGCGTGGTTATAGATGAAACGCAATCAGAGGAGGAAGAGTCCCAGTCGAGTGAGACTGCGGAATCCGAAAAG

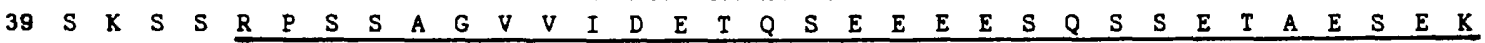
298 TCCGATGAGTCCGACAACTCGCAAAATTCCCAGGAGTCAGAAGACTCTGAGGACGACAGCGTTCGICCGTCCGCTAGGAACACTAAGAGGAAGCCTTG \begin{tabular}{llllllllllllllllllllllllllllllllllll}
72 & $S$ & $D$ & $E$ & $S$ & $D$ & $N$ & $S$ & $Q$ & $N$ & $S$ & $Q$ & $E$ & $S$ & $E$ & $D$ & $S$ & $E$ & $D$ & $D$ & $S$ & $V$ & $R$ & $P$ & $S$ & $A$ & $R$ & $N$ & $T$ & $K$ & $R$ & $K$ & $P$ & $L$ \\
\hline
\end{tabular} 397 GGAATCCCCTCCGATAGCGAGGATGAGGAGGACGAGCTGGAACAGCGCGCTTTGTCACCCAGCACCCGCATGAGCATCACTGGAGTGCGGCCTCAGGAT \begin{tabular}{lllllllllllllllllllllllllllllllllll}
105 & $G$ & $I$ & $P$ & $S$ & $D$ & $S$ & $E$ & $D$ & $E$ & $E$ & $D$ & $E$ & $L$ & $E$ & $Q$ & $R$ & $A$ & $L$ & $S$ & $P$ & $S$ & $T$ & $R$ & $M$ & $S$ & $I$ & $T$ & $G$ & $V$ & $R$ & $P$ & $Q$ & $D$ \\
\hline
\end{tabular} 496 CTCAGCGATGACGACAGCGAGATCGAGTACAGCGATGAAGTGCAGGAGGACCCACGGAGGCACCCACTGCCGAAGCGGTCGTGCCCGGCTACACCACA \begin{tabular}{lllllllllllllllllllllllllllllllllll}
138 & $L$ & $S$ & $D$ & $D$ & $D$ & $S$ & $E$ & $I$ & $E$ & $Y$ & $S$ & $D$ & $E$ & $V$ & $Q$ & $E$ & $G$ & $P$ & $T$ & $E$ & $A$ & $P$ & $T$ & $A$ & $E$ & $A$ & $V$ & $V$ & $P$ & $G$ & $Y$ & $T$ & $T$ \\
\hline
\end{tabular} 595 CAGTTTGCTGGTAATATACAGAACGACCTCCATTCGACGATTGGCGCTGCGGATTCTGAGGTCTTGGACGACTCCAGTGGCAGTGATGTGCTCATACTC

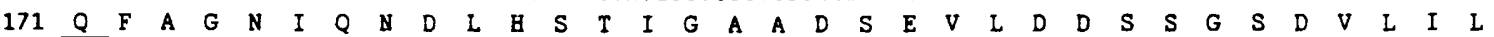
694 AGCAACAAGGAGACACCTATTGAGATACTATCCAGCACAGACGACGATGCCACCACCAATAAGGAAAACATGTCCGGCCCCCGTTTGAACGCCCATCA

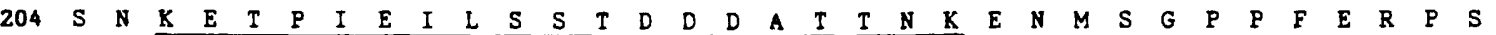
793 AAGTCTTTGTCGCCAGAAGCAGTGCTGGCGCTTCGGTGTCAAGACAAGCAAGATCTCAGTCAGCCAACAATACAAGCGGTTCTTAAGCAAAGACA

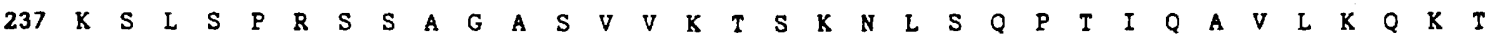
892 TCTCCTGCCGCTCCACGTCGATCTCGGATTAAGAGCGAGGACCAGAAGGTGGTCAGCCAGGTGGTCTACGATGAGGAGATGCGTAAGCTGGCCGAAAAG $\begin{array}{llllllllllllllllllllllllllllllllllllll}270 & S & P & A & A & P & R & R & S & R & I & K & S & E & D & Q & K & V & V & S & Q & V & V & Y & D & E & E & M & R & K & L & A & E & K\end{array}$ 991 CGCGTTCAGGTAAGCGATGCGGAGAAGCTCTTCGAGAAAGTGGCCCACAAGCTGCCCGATAAGGGCAGCCAGATTATGAAGCGCATTGACACCCTGCGC $\begin{array}{lllllllllllllllllllllllllllllllllll}303 & R & V & Q & V & S & D & A & E & K & \text { L } & F & E & K & V & A & \text { G } & K & \text { L } & \text { P } & D & K & G & \text { S } & Q & I & M & K & R & I & D & I & L & R\end{array}$ 1090 CGTGAGCTCGCAATGGACGAGCAATGGATTAGCGCACTAAGGGTTCAGCAGAGTAATGTGCCTGCCGTCAGAGTGGTTAAGCCAACACTAAATCCACCC $\begin{array}{lllllllllllllllllllllllllllllllllllll}336 & R & E & L & A & M & D & E & Q & W & I & S & A & L & R & V & Q & Q & S & N & V & P & A & V & R & V & V & K & P & T & L & N & P & P\end{array}$ 1189 AGAGCTCCATCAATCGATACTCTTGACTGGGATGAGTTGTCGGAGGCGGTCAATGAAATAAAGCCCGTCTACACGGGTGCCCAAGGAATGGCCACATTI $\begin{array}{lllllllllllllllllllllllllllllllllllll}369 & R & A & P & S & I & D & T & L & D & W & D & E & L & S & E & A & V & N & E & I & K & P & V & Y & T & G & A & Q & G & M & A & T & F\end{array}$ 1288 AACAACCAGAAGGCACTGACCCTGGAATCGCTAAAGGACCTCCACGTCTCACTCGAGGACCTTCCTGGACCCGAAGTGCTCGCAGAGGACCCTGTTGGC $\begin{array}{lllllllllllllllllllllllllllllllllllll}402 & N & N & Q & K & A & L & T & L & E & S & L & K & D & \text { L } & \text { B } & \text { V } & \text { S } & \text { L } & E & \text { D } & \text { L } & P & G & P & E & V & L & A & E & D & P & V & G\end{array}$ 1387 CTGAAGTIATCGCTTATGAACCACCAAAAGCACGCCTTAGCCTGGATGTCCTGGCGTGAACGTAAACTACCTCGGGGAGGAATCCTGGCGGACGATATG \begin{tabular}{lllllllllllllllllllllllllllllll|lllllll}
435 & $L$ & $K$ & $V$ & $S$ & $L$ & $M$ & $N$ & B & $Q$ & $K$ & B & $A$ & L & $A$ & W & $M$ & $S$ & W & $R$ & $E$ & $R$ & $K$ & L & $P$ & $R$ & $G$ & $G$ & I & L & $A$ & $D$ & $D$ & $M$ \\
\hline
\end{tabular} 1486 GGTTTGGGCAAGACTCTAACCATGATCTCGTCTGTCCTCGCTTGCAAAAATGGCCAAGAAATGTCCGAAGGCAAAGATGAGAGCAGTGACAGCGACAGT 468 G 1585 GAGGATGATAAAAATAAGAGGGAAAAAGCGTGACCGGATGGAAATCCAAGGGCCGTAAAGATACGCGTAGGGGCGGCACATTGGTGGTGTGTCCTGCC

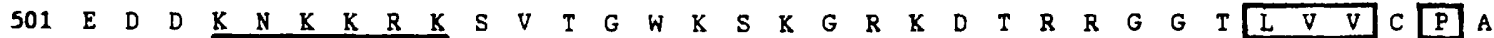
1684 AGCTTGCTGCGTCAGTGGAGAGCGAGGTGGAGTCGAAGGTTTCGCGTCAGAAGCTGACCGTTTGCGTGCACCATGGCAACAATCGGGAGACGAAGGGA $\begin{array}{lllllllllllllllllllllllllllllllllll}534 & S & L & L & R & Q & W & E & S & E & V & E & S & K & V & S & R & Q & K & L & T & V & C & V & \text { H } & \text { B } & G & N & N & R & E & T & K & G\end{array}$ 1783 AAGTACCTTCGAGACTACGATATTGTGGTGACAACCTACCAAATTGTGGCGCGGGAGCACAAGAGCTTGAGTGCTGTGTTTGGTGTCAAGTGGCGGCGG $\begin{array}{llllllllllllllllllllllllllllllllllllll}567 & K & Y & \text { L } & R & D & Y & D & I & \text { V } & \text { V } & \text { T } & \text { T } & \text { Y } & \text { Q } & \text { I } & \text { V } & \text { A } & R & \text { E } & \text { H } & \text { K } & \text { S } & \text { L } & \text { S } & \text { A } & \text { V } & F & G & \text { V } & K & W & R & R\end{array}$ 1882 ATCATTTTGGACGAGGCGCACGTGGTGCGCAATCATAAATCGCAGTCATCATTGGCGGTGTGTGATTTACGTGGCAAATATCGTTGGGCATTGACTGGC 600 I 1981 ACTCCTATTCAAAACAAGGACTGGATGTCTATGCCCTGCTCAAGTTCTTGCGCTGCTCGCCCTTTGATGATTTACACACGTGGAAGAAGTGGATTGAC 633 I 2080 AACAAGAGTGCTGGAGGGCAAAACCGGCTCAATCTGCTAA TGAAGTCACTCATGCTAAGGCGCACCAAAGCACAGTTGCAATCGGACGGCAAGCTGAAC $\begin{array}{lllllllllllllllllllllllllllllllllllll}666 & N & K & S & A & G & G & Q & N & R & L & N & L & L & M & K & S & L & M & L & R & R & T & K & A & Q & L & Q & S & D & G & K & L & N\end{array}$ 2179 AGCTTGCCCAATAAAGAGCTGCGCCTGATCGAGATCTCGCTGGACAAGGAGGAGATGAATGTTTACCAAACTGTAATGACTTATTCCAGGACACTGTTC 699 S 2278 GCTCAGTTTCTCCATCAGCGCGCCGAGAGAGAAACTGATTTTAATTACAGAAGCGATGCCAATAAACCAACCTACAATCAAATTAAAGATCCCAATGGG $\begin{array}{llllllllllllllllllllllllllllllllllll} & 732 & A & Q & F & L & B & Q & R & A & E & R & E & T & D & F & N & Y & R & S & D & A & N & K & P & T & Y & N & Q & I & K & D & P & N & G\end{array}$ 2377 OCATATTACAAATGCACGAAAAGTTTGCCAGAATGGCTGGAAGCAAAAGGAGGTAAAATCTCATGATATATTGGTGTTACTGCTGCGTCTTCGACAA $\begin{array}{lllllllllllllllllllllllllllllllllllllllllll}765 & A & Y & Y & K & M & B & E & K & F & A & R & M & A & G & S & K & K & E & V & K & S & \text { B } & D & I & L & V & L & L & L & R & L & R & Q\end{array}$ 2476 ATTTGCTGTCATCCTGGCCTTATTGATGCGATGCTGGATGGAGAGGAATCCCAGACCATGGGAGACCACAGTAGTGACAGCGATACACCCGAAATCGAT 798 I $C$ C 2575 ITGTTGGCCCAGCTCAATAAACTCGCAATTACGGACACCTCCACCGACGGTCAGCAATCGGTTGCCAATGCAGGTGACGACGGTCCTCCGCTATTGCCG

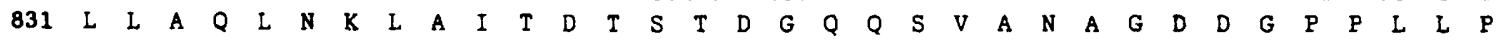
2674 GATGAAGCCCGCATTGCCAAGGCCTCCAAAAATCTGCTGAAACGCAGCAACCCGGTATTTAATCTGCATCGTCCCTCTTCAAAAATTAACATGGTGATA

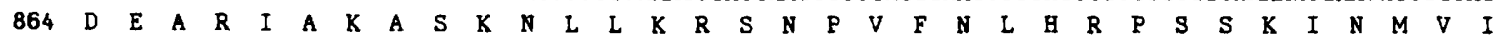
2773 CAAATCCTTAAGACATCGATTCTGAAGAGCTCGGACGACAAGGCCATAGTAGTATCTCAGTGGACGTCAGTGTTAGACATTCTTCGCGACCATTTGAGT

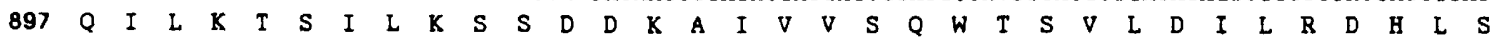
2872 AAGGATGGTGTGGCGACCTTATCATTAAACGGTACCATTCCGGTTAAAAACCGTCAGACATTGTTAATGAGTTCAACGATCGCAACAATCAGAAGCGCG

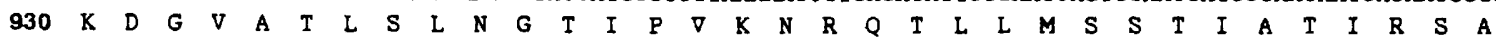
2971 TICTCTTGCTTTCCCTTACTGCTGGCGGTGTGGGTTGAacctgattggtgecaecacctgttgcttttggatctgcactggaatcctcagttggagB

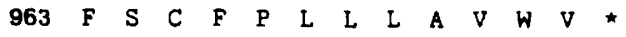

3070 ctcaggcccaggaccgtatataccgCgttg8ccaaaaagaacg tgatcatttatagettcatgtgcgtggacacagttgagcagcggatcaaaggat

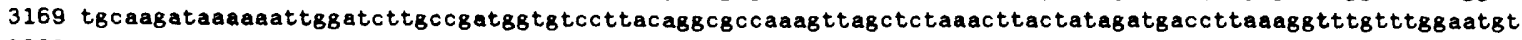
3268 gagcttgcttttaacgtttcgtattttatcacttccatacttatttttgtcgttt.gcaaatgcattccatagataccattttatgtttatttaca

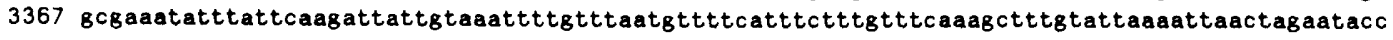

Figure 5. (See facing page for legend.) 


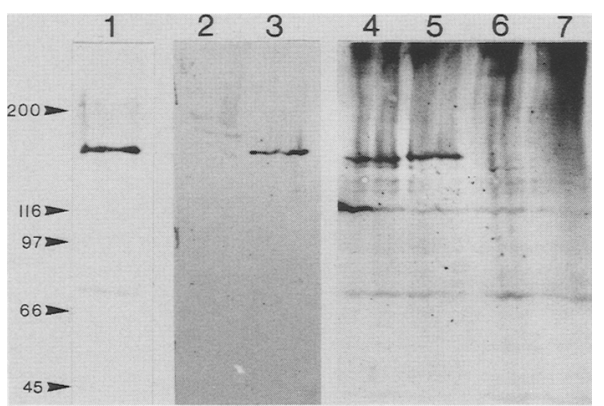

Figure 6. The anti-lodestar antiserum recognizes a protein of $155 \mathrm{kD}$. Western blot strips were prepared and probed with antilodestar antiserum as detailed in Materials and methods. (Lane 1) 0- to 3-hr embryos; (lane 2) adult female carcass (females from which the ovaries have been removed); (lane 3) ovaries dissected from adults; (lane 4-7) ovaries dissected from adult females hemizygous for lodestar. Females were of the genotype lodestar/Df(3R)dsx21: (Lane 4) $1 d s^{042-13}$; (lane 5) 1ds ${ }^{352-16}$; (lane 6) $1 d s^{098-1}$; (lane 7) $1 d s^{298-8}$. Lanes 4-7 were deliberately overdeveloped to verify the absence of lodestar protein in $1 d s^{098-1}$ and $1 d s^{298-8}$. The protein detected in embryo extracts is considerably larger than that predicted from translation of the cDNA sequence. This may result from post-translational modification such as phosphorylation or glycosylation. There are a number of potential target sites for post-translational modification in the lodestar sequence.

axis aligned with that of the mitotic spindle (Fig. 8A). It is probable that the distribution of the lodestar protein is delimited by the spindle envelope during metaphase and anaphase A (Fig. 8A,B). Drosophila is intermediate between those organisms having "open" spindles (such as mammals), in which there is complete breakdown of the nuclear envelope during mitosis, and those having "closed" spindles (such as yeasts and diatoms), in which the nuclear envelope remains intact throughout mitosis. In Drosophila, the nuclear envelope only breaks down at the poles of the spindle, and during prometaphase a second membrane begins to form around the nuclear envelope. This second membrane, which is referred to as the spindle envelope, is completed by metaphase but never extends to the poles (Stafstrom and Staehelin 1984). The observation that lodestar protein does not extend to the poles of the spindle (not shown) supports the view that the spindle envelope provides the boundary to the distribution of the lodestar protein.

The long axis of the diamond of the lodestar protein extends as the chromatids are separated at anaphase A (Fig. 8B). As the chromatids reach their full separation at the end of anaphase B, the lodestar protein becomes localized over the chromatin and is cleared from the region between the two prospective daughter nuclei (Fig. 8C). As the chromatin decondenses in telophase, the lodestar protein becomes entirely localized within the reforming nuclear envelope surrounding the daughter nuclei (Fig. $8 \mathrm{D})$. The lodestar protein is removed from the nucleus as it re-enters interphase at the beginning of the next cycle.

\section{Discussion}

The lodestar protein is one of a number of Drosophila proteins whose nuclear localization is regulated during embryonic development. A gradient of nuclear localization of the dorsal transcription factor has been shown to determine pattern on the dorsal-ventral axis in Drosophila (Roth et al. 1989; Rushlow et al. 1989; Steward 1989|, and several proteins thought to be involved in transcriptional processes are initially cytoplasmic in the early Drosophila embryo but redistribute into the nuclei at cycle $11 / 12$, approximately corresponding to the onset of zygotic transcription (Dequin et al. 1984). Whereas these two examples from Drosophila show the use of compartmentalization to regulate nuclear functions unrelated to the cell cycle, the subcellular distributions of the products of the SWI5 and the CDC46 genes of Saccharomyces cerevisiae are regulated in a cell cycle-dependent manner. The SWI5 protein is a transcription factor required for the expression of the $H O$ gene involved in mating-type switching, which accumulates in the cytoplasm during anaphase and only moves into the nucleus as the cells enter $G_{1}$, when the $H O$ gene is transcribed (Nasmyth et al. 1990). The CDC46 protein, which is thought to be involved in the initiation of DNA replication, moves rapidly from the cytoplasm into the nucleus as the cells complete mitosis and remains in the nucleus until the next round of DNA replication is initiated. The $C D C 46$ protein disappears from the nucleus after the cell becomes committed to division (Hennessy et al. 1990). Blow and Laskey (1988) suggest that protein compartmentalization between the nucleus and the cytoplasm may be important in ensuring that the genome is replicated only once per cycle.

The most obvious advantage of regulating the nuclear entry of a protein is the ability to achieve an extremely rapid change in protein concentration. A large store of

Figure 5. Sequence of the lodestar NBA1 cDNA clone. The 3456 bp sequence of lodestar cDNA NBAl with a translation of the largest open reading frame is shown. The nucleotide sequence of the open reading frame is shown in uppercase letters. Untranslated sequence is shown in lowercase letters. The nucleotide and putative protein sequences are numbered at left. Poly(A) is attached to the last nucleotide in the sequence and utilizes a consensus polyadenylation signal sequence ATTAAAA (Birnstiel et al. 1985). Potential PEST sequences are underlined and were identified by using the PESTFIND computer program (Rogers et al. 1986). The PESTFIND scores for the four PEST sequences (in order from the amino terminus): 18.6, 15.8, 7.3, and 10.8. The motifs of a potential NTP-binding site are boxed. Amino acid residues $462-474$ correspond to the A box of the NTP-binding site (Walker et al. 1982) and contain the invariant GXGKS/T sequence ( $\mathrm{X}$ is any residue). Residues 600-606 correspond to the B box of the binding site (Walker et al. 1982), with the highly conserved DE pair at position 603 . The two other boxed sequences, residues 528-532 and 631-634, correspond to two less highly conserved motifs identified in the NTP-binding sites of a superfamily of nucleic acid-dependent helicase proteins (Gorbalenya et al. 1989; motifs Ia and III, respectively). A potential nuclear localization signal (residues 504-509) is underlined with a heavy bar. 
A
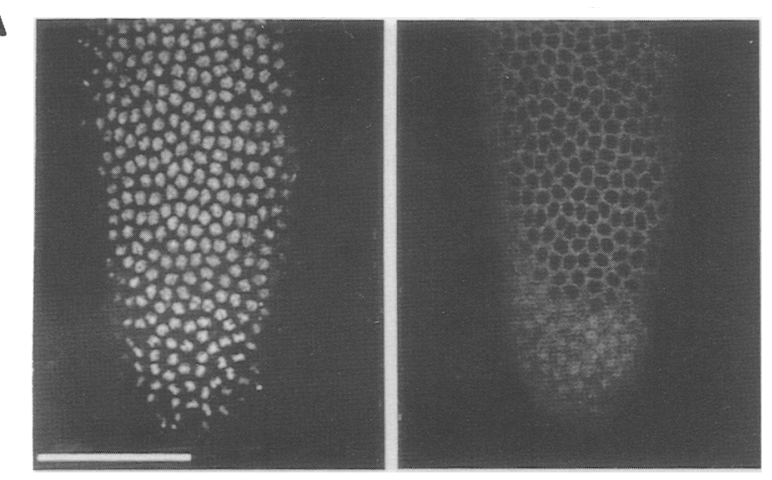

$\mathbf{B}$
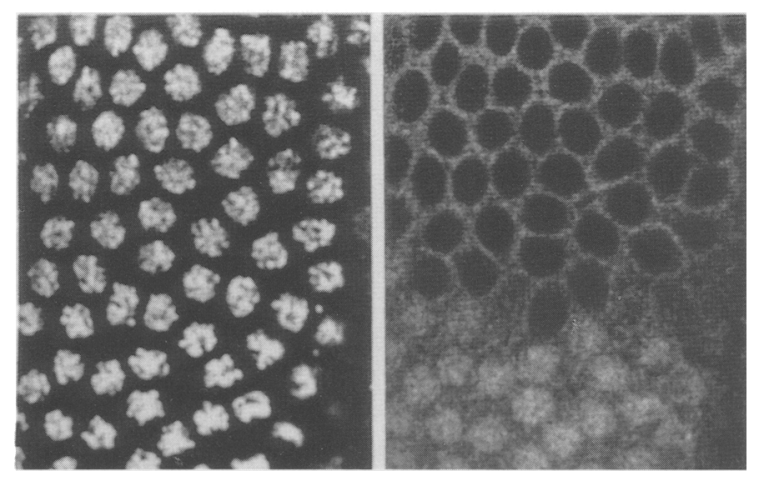
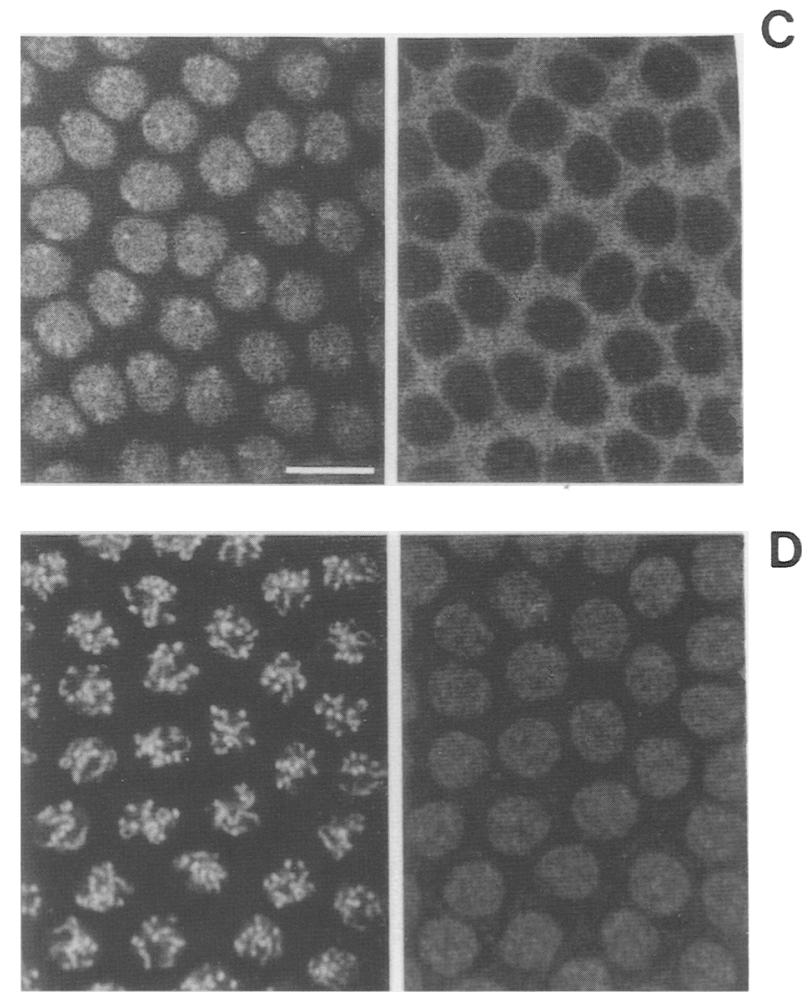

Figure 7. The lodestar protein redistributes rapidly from the cytoplasm to the nucleus after the beginning of prophase. $A-D$ are images from a laser-scanning confocal microscope and show the distribution of DNA stained with propidium iodide (left), and the corresponding lodestar protein distribution (right). (A) A mitotic wave (Foe and Alberts 1983) traversing an embryo. The nuclei toward the bottom are slightly farther advanced into $M$ phase of cycle 12 than the nuclei nearer the top. Bar, $100 \mu \mathrm{m}$. $(B)$ An enlargement of the region where the lodestar protein is undergoing redistribution from the cytoplasm to the nucleus. Bar, $10 \mu \mathrm{m}$. The redistribution process is exceptionally rapid, as there are few nuclei at intermediate stages. $(C, D)$ Fields from cycle 12 embryos. $C$ shows interphase, with lodestar protein in the cytoplasm; $D$ shows prophase, with lodestar protein entirely within the nucleus. Bar, $10 \mu \mathrm{m}$.

protein can be maintained in the cytoplasm away from its site of action and then instantly be allowed access to a nuclear location where its function is required. The rapidity with which the lodestar protein redistributes to the nucleus strongly suggests an active process. At the stage at which the protein enters the nucleus, the nuclear envelope and its associated nuclear pore complexes, which are likely to mediate the import of cytoplasmic proteins, are essentially intact (Stafstrom and Staehelin 1984). Modulation of the accessibility of the lodestar nuclear localization signal to receptors in the nuclear pores, through changes in levels of phosphorylation, for example, may be an important factor in controlling the entry of the protein into the nucleus. Transience in the elevation of protein concentration may also be important for the execution of a function that must occur only at a precise point in the cycle, and it may be equally significant to the embryo that lodestar protein is not present in the nucleus during $\mathrm{S}$ phase of the cycle. The lodestar protein seems to be rapidly removed from the nucleus as it re-enters interphase. We have yet to address the question of whether it is exported from the nucleus or is degraded in the telophase nucleus with resynthesis in the cytoplasm. The strong PEST sequences identified in the amino-terminal portion of lodestar may target it for proteolysis within the nucleus at this point in the cycle, although such a mechanism may only operate at later developmental stages as is the case with the cyclical degradation of cyclins A and B (G. MaldonadoCodina and D.M. Glover, in prep.). Nasmyth and colleagues (1990) suggest that the SWI5 protein may be less stable in the nucleus than in the cytoplasm, although they do not rule out the fact that changes in the stability of the protein may be the result of the phase of the cycle rather than compartment-specific effects. If the string of basic amino acids in the protein is a regulated NLS, we are in a position to mutate this sequence to address the question of whether the compartmentalization of the lodestar protein in the embryonic mitotic cycles reflects its function.

The phenotype of lodestar mutations is first apparent when chromatids have begun separating in anaphase. However, it is possible that the function of the lodestar protein is required earlier in the cycle and that the defect may only become visible after the onset of anaphase. The formation of anaphase bridges appears to be a specific characteristic of lodestar mutations, and as it is the first defect to become apparent in LDS embryos, we feel that it reflects the primary effect of the mutations. The rapid entry of the lodestar protein into the nucleus early in 
Drosophila mutation causing anaphase bridges
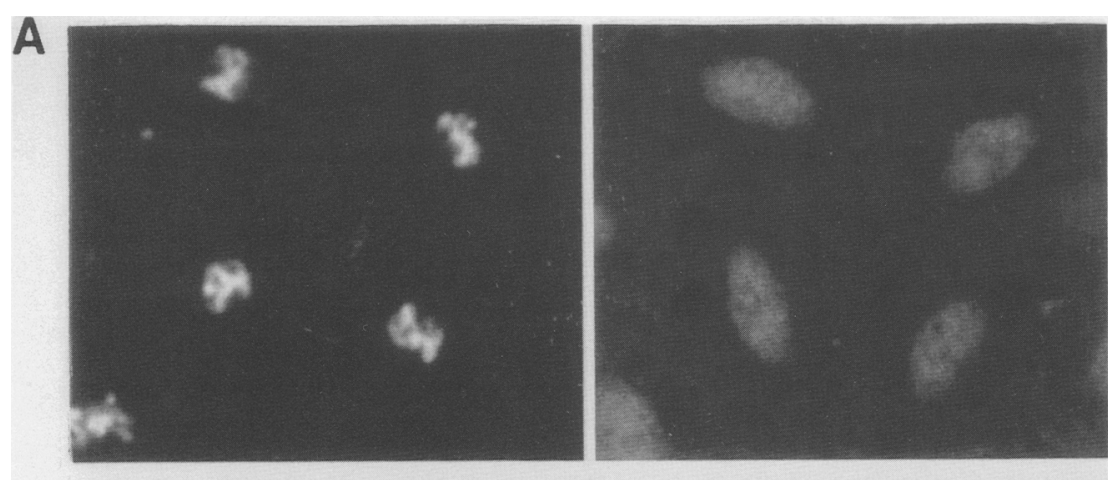

B
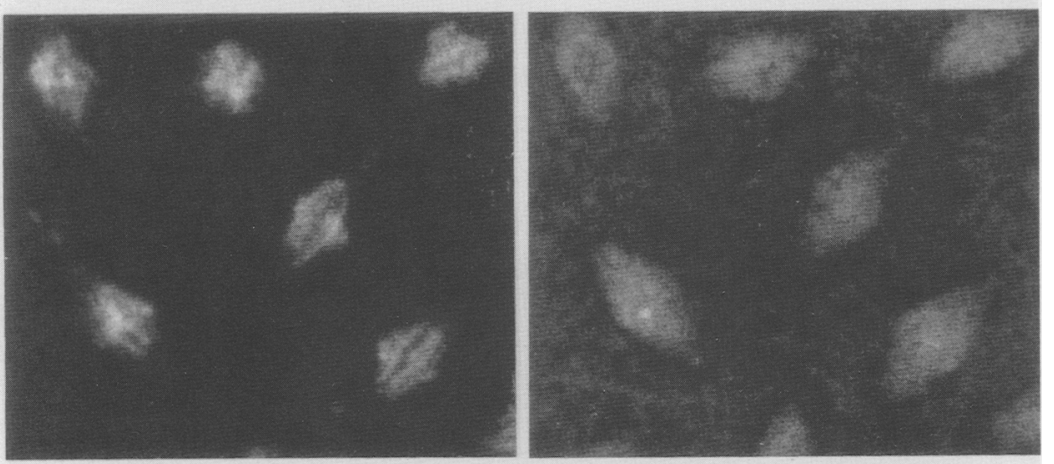

C
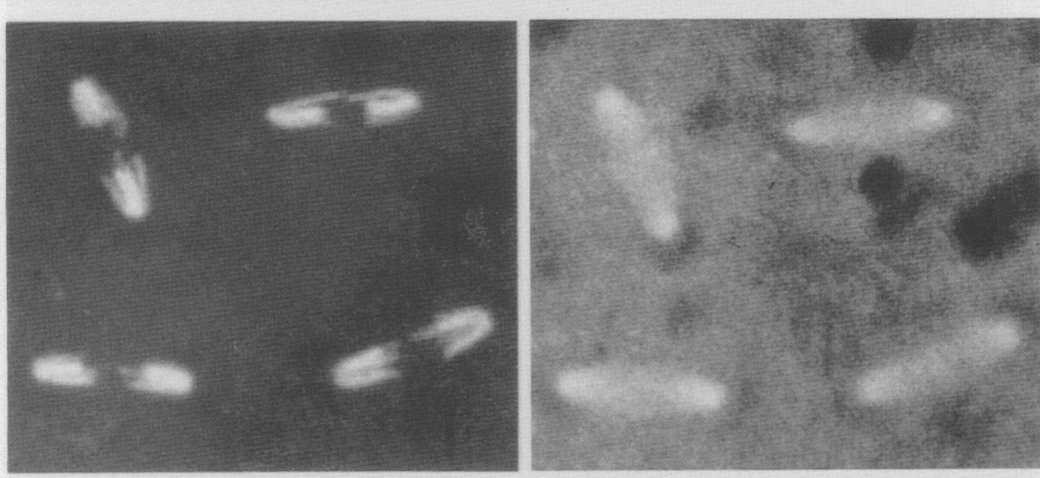

D
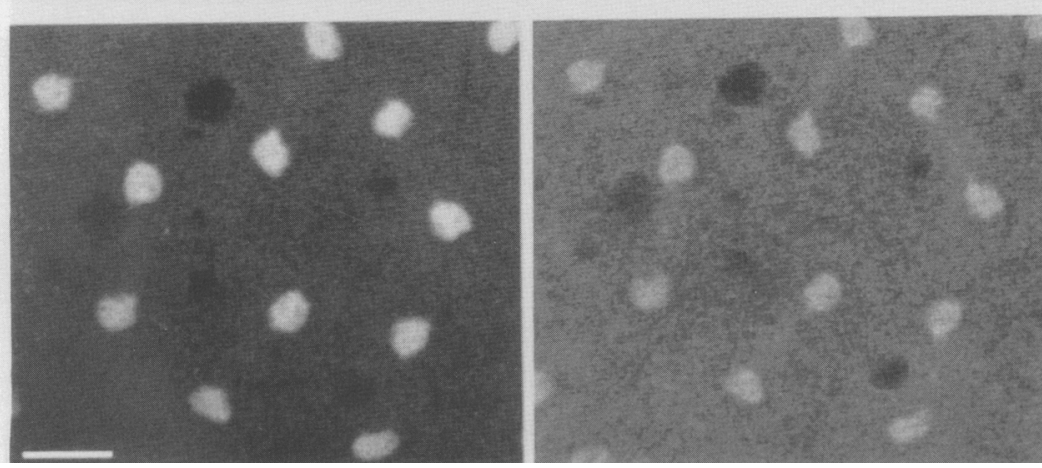

Figure 8. Distribution of the lodestar protein between metaphase and telophase. $A-D$ are images obtained with a laser-scanning confocal microscope and show fields from wild-type embryos at syncytial cycle 10. DNA stained with propidium iodide is at left; the corresponding distribution of the lodestar protein, detected with the polyclonal antisenum, is at right. (A) Metaphase; $(B)$; early anaphase $A_{;}(C)$ anaphase $B_{i}(D)$ telophase. Bar, $10 \mu \mathrm{m}$. prophase might suggest that the function is necessary at this stage of the cycle or, at least, that the protein must be in the nucleus at this stage to execute its function correctly at some later point. However, we have been unable to define a consistent abnormality in prophase or metaphase nuclei in LDS embryos using immunofluorescence microscopy.
The existing lodestar mutations suggest a greater requirement for lodestar function in early embryogenesis compared with later development. All four mutant alleles have strong maternal effects and are hemizygous viable, suggesting that they may not represent weak hypomorphic alleles of an essential zygotic function (Perrimon et al. 1986). lodestar may not define a lethal 
complementation group, as a saturation mutagenesis screen of the region around the doublesex locus failed to identify any zygotic lethal mutations between the distal breakpoints of the Df(3R)Antp17 and Df(3R)dsx2M chromosomes, which delimit the position of the lodestar gene (Baker et al. 1991). The perdurance of lodestar protein and/or transcript deposited in the oocyte may be entirely sufficient to allow the development of an adult organism, or alternatively, other gene products may compensate for the absence of lodestar function during the development of the imaginal tissues. The similar cell division phenotypes observed in LDS embryos and larval neuroblasts, however, suggest that lodestar has an equivalent function at both of these periods of development.

Chromatin fragmentation in LDS embryos and larval neuroblasts indicates that the forces exerted at anaphase can cause breakage rather than resolution of the chromatin bridges and tangled masses of chromatin, and suggests that the chromatin must be firmly interconnected in the presence of lodestar mutations. We consider that defects in three major processes could lead to physical interconnection of chromatin and cause a phenotype of chromatin bridging at anaphase: errors in the mechanisms that pull chromatids to opposite poles in anaphase; incomplete DNA replication or repair; or failure in the topological manipulation of DNA during chromatin condensation.

Other Drosophila genes have been characterized that show anaphase bridges as the major defect: $1(1) \mathrm{TW}-6^{\text {cs }}$ and $f_{s}(3) 2755$ (Gatti et al. 1983); rough deal also shows some similarities in that mutations lead to lagging chromatids and chromatid breakage (Karess and Glover 1989|. Of these genes, only $1(1) T W-6^{c s}$ has been characterized at the molecular level: It is an antimorphic allele of the nod gene, encoding a kinesin-like force-generating molecule (Zhang et al. 1990). However, the $1(1) T W-6^{c s}$ mutation behaves as a simple dominant one with respect to mitosis, and there is no evidence that recessive lossof-function mutations in this gene can cause the formation of chromatin bridges (Zhang et al. 1990). The cut class of $S$. pombe mutations cause cell division in the absence of nuclear division and produce daughter nuclei joined by chromatin filaments (Hirano et al. 1986). One of these genes, cut7, encodes a protein that also shows homology to kinesins (Hagan and Yanagida 1990). The movement of lodestar protein into the compartment occupied by the spindle could suggest a role for the protein as part of the mechanism whereby force is exerted on the chromatid arms.

A defect causing incomplete replication of the DNA might also lead to a phenotype of chromatin bridging, as entry into mitosis is not dependent on the completion of DNA replication during the syncytial nuclear cycles (Raff and Glover 1988). However, entry into mitosis becomes dependent on the completion of DNA replication after cellularization (Edgar and O'Farrell 1990), and chromatin bridges are also observed in cellularized LDS embryos. This could imply either that chromatin bridging and tangling in LDS embryos are not caused by incomplete DNA replication, or that the lodestar protein is a component of the mechanism that links entry into mitosis to the completion of DNA replication. The extent of development of LDS embryos (Fig. 1H,I) and the absence of the protein from the nucleus during $S$ phase suggests that lodestar is not an essential component of the DNA replication machinery. The variable limits of development of LDS embryos could be the result of environmental factors or, alternatively, a requirement for the lodestar function in a process that is not utilized in every nucleus at every cycle but is nevertheless essential during embryogenesis. A DNA repair function may only be required in those nuclei in which errors occur during replication. There may be an important demand for DNA repair activities in the syncytial Drosophila embryo with its exceptionally rapid $S$ phases. The need to complete nuclear division cycles in times as short as 8 min may mean that the repair of errors incurred during $S$ phase must take place during $M$ phase of the cycle. It is possible that DNA repair could occur in prophase before complete condensation of the chromatin or at telophase as chromatin decondenses just before the beginning of the next $\mathrm{S}$ phase.

Abnormalities in chromosome condensation might also cause chromatin to remain interconnected at anaphase. In the yeast $S$. pombe, the top 2 gene, encoding a DNA topoisomerase type II enzyme, is essential both for chromosome condensation and chromosome separation at anaphase (Uemura et al. 1987). Mutations affecting chromosome condensation in Drosophila often show significant levels of chromosome breakage (Gatti and Baker 1989), however, chromosome condensation is not obviously affected in lodestar mutants.

The three major processes mentioned above as possible sources of a chromatin-bridging phenotype would all be dependent on NTP hydrolysis. The lodestar protein has a putative NTP-binding site and could also possess NTP hydrolysis activity. The sequence of the NTP-binding site is related to that of the D-E-A-H superfamily of proteins, but unlike other members of this family, lodestar appears to lack the nucleic acid helicase domain. Perhaps this, or alternative functions, could be supplied by interacting subunits. The availability of antibodies against the lodestar gene product will now permit a biochemical analysis of potential interactions with other proteins. Determination of the position of lodestar in the mechanical or regulatory network that controls mitosis awaits further genetic analysis of the interaction of lodestar mutations with mutations in other cell division genes and the identification of additional genes that may be related to it either structurally or functionally.

\section{Materials and methods}

\section{Drosophila stocks}

The lodestar alleles were provided by Christiane Nüsslein-Volhard. lodestar alleles $1 d s^{042-13}, l d s^{098-1}$, and $1 d s$ sup298-8 were induced on ru st e ca chromosomes. The $1 d s^{352-16}$ allele was induced on a ru th st ri roe $p^{P} e^{8} c a$ chromosome (for full descriptions of the phenotypes of these visible mutations, see Lindsley and Zimm 1985, 1990). These mutations were bal- 
anced over the TM6B chromosome carrying the larval marker Tubby, which allowed larvae homozygous for lodestar to be identified. The lodestar mutation was mapped to $3-47.8$ by recombination between Lyra (3-40.5) and Stubble (3-58.2) by Jordan Raff in this laboratory and also by recombination between scarlet (3-44.0) and curled (3-50.0). The Df(3R)dsx21 chromosome (deleted for $84 \mathrm{D} 11-12 ; 84 \mathrm{E} 8-9$ ) was used to generate animals hemizygous for lodestar. We are grateful to T.C. Kaufman for providing the $\mathrm{Df}(3 \mathrm{R})$ Antp17 chromosome and the Bloomington Stock Center for providing many other $\mathrm{Df}(3 \mathrm{R})$ stocks in this region. B.S. Baker provided the $\mathrm{Df}(3 \mathrm{R}) d s \times 2 M$ chromosome and several other $\operatorname{Df}(3 \mathrm{R}) d s x$ chromosomes used.

\section{Larval neuroblast squash preparations}

The methods used have been described previously /Gonzalez et al. 1988; Axton et al. 1990).

\section{Staining of embryos for indirect immunofluorescence microscopy}

Embryos were fixed in $3.7 \%$ formaldehyde $137 \%$ stock, Fisons Analar grade, containing $10-14 \%$ methanol as stabilizer) essentially as described previously (Whitfield et al. 1990). Microtubules could be stabilized by incubating with $5 \mu \mathrm{M}$ taxol (gift of Dr. M. Suffness, National Cancer Institute) for $30 \mathrm{sec}$ prior to fixation. Antibodies were used at concentrations suggested by the manufacturers. The anti-tubulin antibody was YL1/2, a rat monoclonal antibody (Sera-Lab). Polyclonal sera were used at $1: 100$ to $1:: 1000$ dilutions. All second antibodies were obtained from Jackson Immunoresearch, Inc. A fluorescein-conjugated anti-rabbit IgG from Sigma Chemical Co. was also used.

\section{P-element-mediated germ-line transformation of Drosophila}

All constructs were made in the vector pW8 (Klemenz et al. 1987). These constructs were injected into embryos from the white stock $w^{1118}$ (gift of Kevin $\mathrm{O}^{\prime} \mathrm{Hare}$ ). The solution for injection consisted of construct at $500 \mu \mathrm{g} / \mathrm{ml}$ and "helper" pUChsII $\Delta 2-3$ (gift of Andrew Tomlinson) at $150 \mu \mathrm{g} / \mathrm{ml}$ in $5 \mathrm{~mm}$ $\mathrm{KCl}, 0.1 \mathrm{~mm}$ phosphate. Embryos were injected at $18^{\circ} \mathrm{C}$ with a Leitz micromanipulator. After injection the embryos were allowed to recover at $18^{\circ} \mathrm{C}$. First-instar larvae were removed from the Voltalef oil, placed on standard fly food, and transferred to $25^{\circ} \mathrm{C}$. Adult flies were mated to $w^{1118}$ virgin females or males. The progeny from this cross was scored for a white ${ }^{+}$phenotype.

\section{Molecular biology}

Standard molecular biological techniques (Sambrook et al. 1989| were used. Sequencing was carried out by using the chaintermination method of Sanger et al. (1977). Sequencing reactions utilized the Sequenase kit (U.S. Biochemical Corporation), and the protocol supplied by the manufacturer was followed exactly. Single-stranded templates for sequencing were generated from fragments cloned into $\mathrm{Ml} 3$ or by strand rescue from fragments cloned into Bluescript vectors (Stratagene). Some double-stranded sequencing was also carried out, in which case the DNA was denatured with $0.2 \mathrm{M} \mathrm{NaOH}$ and then precipitated immediately with ammonium acetate and ethanol prior to annealing the primer.

\section{SDS-polyacrylamide gel electrophoresis of proteins and Western blotting}

Proteins were analyzed by using a two-phase SDS-polyacrylamide gel system. The separating gel contained $7.5 \%$ acrylamide, Tris- $\mathrm{HCl}(\mathrm{pH} 8.8)$, and the stacking gel was $3 \%$ acryla- mide, Tris- $\mathrm{HCl}(\mathrm{pH} 6.9)$. Samples were homogenized in a $1.5-\mathrm{ml}$ microcentrifuge tube and boiled for $5 \mathrm{~min}$ in sample buffer $[2.0 \%$ SDS, $0.125 \mathrm{M}$ Tris- $\mathrm{HCl}(\mathrm{pH} 6.9), 5.0 \%$ 2-mercaptoethanol, $10 \%$ glycerol, bromophenol blue] prior to loading.

Western blotting was carried out by sandwiching the gel tightly against a piece of nitrocellulose and transferring in transfer buffer $(0.025 \mathrm{M}$ Tris, $0.191 \mathrm{M}$ glycine at $\mathrm{pH} 8.5)$. The nitrocellulose filter was blocked for at least $1 \mathrm{hr}$ in "blocking mix" [phosphate-buffered saline (PBS) containing $2 \%$ powdered milk, $20 \mathrm{~mm}$ sodium azide, and $0.1 \%$ Tween 20$]$. The polyclonal serum was diluted to between $1: 200$ and $1: 1000$ in the blocking mix and incubated with the blot in a sealed bag on a rotating blood mixer, overnight at $4^{\circ} \mathrm{C}$. The blot was then washed over a period of $30 \mathrm{~min}$ in PBS containing $0.1 \%$ Tween 20 . The peroxidase-conjugated second antibody (Jackson), at a dilution of $1: 1000$ in the blocking mix, was incubated with the blot for 2-4 hr at room temperature. The filter was washed as before with the incorporation of a final wash in PBS containing no detergent and then incubated with occasional shaking in PBS containing $0.5 \mathrm{mg} / \mathrm{ml}$ of 4-chloro-1-naphthol and $0.02 \%$ hydrogen peroxide for up to $10 \mathrm{~min}$ to visualize antibody binding.

\section{Purification of $\beta$-galactosidase/lodestar fusion protein and preparation of antisera}

A protocol to enrich for the $\beta$-galactosidase fusion protein was devised on the basis of methods described by Carroll and Laughon (1987). Initial experiments determined that the $\beta$-galactosidase fusion protein was deposited in inclusion bodies (Marston 1987). The following method gives a highly enriched preparation of this protein, which is then suitable for preparative gel filtration: Four milliliters of an overnight culture of the appropriate pUR expression vector construct (Ruther and Muller-Hill 1983) in $E$. coli was diluted into $500 \mathrm{ml}$ of Luria-broth containing $500 \mu \mathrm{m} / \mathrm{ml}$ of ampicillin and grown with agitation at $37^{\circ} \mathrm{C}$ for $90 \mathrm{~min}$. IPTG was then added to $0.5 \mathrm{~mm}$ (from a $0.5 \mathrm{M}$ stock solution), and the culture was grown for an additional 2 $\mathrm{hr}$. The cells were pelleted for $5 \mathrm{~min}$ at $7000 \mathrm{rpm}$, drained thoroughly, and then resuspended in 0.02 volumes of lysis buffer [ 50 mM sodium phosphate ( $\mathrm{pH} 7$ ), $10 \mathrm{mM} 2$-mercaptoethanol, $10 \mathrm{mM}$ EDTA, $1 \mathrm{mM}$ pmsf added from a $1 \mathrm{M}$ stock solution made in methanol.] Lysozyme was added to $0.2 \mathrm{mg} / \mathrm{ml}$, and the cells were then incubated on ice for $30 \mathrm{~min}$. The mixture was frozen at $-70^{\circ} \mathrm{C}$ for $30 \mathrm{~min}$ and thawed rapidly in a water bath at $37^{\circ} \mathrm{C}$ to complete the lysis of the cells. The viscosity of the solution was reduced by several medium power bursts with a Polytron. Five $\mathrm{M} \mathrm{NaCl}$ was added to $0.5 \mathrm{M}$ and mixed thoroughly. The extract was clarified at $13,000 \mathrm{~g}$ at $4^{\circ} \mathrm{C}$ for $10 \mathrm{~min}$. The supernatant was discarded, and the cell debris was extracted with $10 \mathrm{ml}$ of urea buffer $[8 \mathrm{M}$ urea, $0.5 \mathrm{M}$ Tris- $\mathrm{HCl}(\mathrm{pH} 7.9), 0.5 \mathrm{M} \mathrm{NaCl}, 1$ mM EDTA, $30 \mathrm{~mm}$ 2-mercaptoethanol, $1 \mathrm{~mm}$ PMSF]. The pellet was vortexed vigorously to solubilize as much of the material as possible before centrifuging. The soluble extract was dialyzed overnight against $50 \mathrm{~mm}$ Tris- $\mathrm{HCl}(\mathrm{pH} 7.9), 0.5 \mathrm{M} \mathrm{NaCl}, 10 \%$ glycerol, at $4^{\circ} \mathrm{C}$. Streptomycin sulfate solution $(0.1$ volume; $30 \% \mathrm{wt} / \mathrm{vol}$ in $50 \mathrm{~mm}$ Tris- $\mathrm{HCl}$, at $\mathrm{pH} 8$ ) was added to the dialyzed extract. After mixing at $4^{\circ} \mathrm{C}$ for $15 \mathrm{~min}$, the extract was centrifuged. Solid ammonium sulfate was then added to the supernatant to give an ammonium sulfate saturation of $40 \%$. After mixing at $4^{\circ} \mathrm{C}$ for $4 \mathrm{hr}$, the precipitated proteins were recovered by centrifugation. The precipitated proteins were found to be enriched for the lodestar fusion protein.

The ammonium sulfate precipitate was dissolved in $2.5 \mathrm{ml}$ of column buffer [20 mM Tris- $\mathrm{HCl}(\mathrm{pH} 7.5), 150 \mathrm{mM} \mathrm{NaCl}, 20 \mathrm{~mm}$ 2-mercaptoethanol, $1 \mathrm{mM}$ PMSF] and applied to a Sephacryl S-300 gel filtration column. The size of the fusion protein on 
denaturing gels was $210 \mathrm{kD}$; this was the largest protein in the extract by a considerable margin, and it eluted just behind the void volume. The purified fusion protein was mixed with two volumes of Freund's complete adjuvant (Sigma) and injected into rabbits at multiple subcutaneous sites. Approximately 100 $\mu \mathrm{g}$ of protein was used per injection. After four boosts in incomplete adjuvant, at monthly intervals, a suitably strong antibody response was generated.

The rabbit polyclonal serum was subjected to affinity chromatography to produce a reagent containing only antibodies against the fusion protein used as an immunogen. A column carrying the fusion protein was constructed as follows: Protein A covalently linked to agarose beads (Sigma no. P2545) was incubated with anti- $\beta$-galactosidase (Sigma no. G4644) for $1 \mathrm{hr}$ at room temperature on a rotating mixer. To this mix was added an extract from an $E$. coli culture expressing the $\beta$-galactosidase/lodestar fusion protein purified as detailed above, without the gel filtration chromatography procedure. After further incubation for $1 \mathrm{hr}$ on the rotating mixer, the beads were washed in $0.2 \mathrm{M}$ sodium borate $(\mathrm{pH} \mathrm{9.2)}$ and resuspended in 10 volumes of $0.2 \mathrm{M}$ sodium borate ( $\mathrm{pH} 9.2$ ), and solid dimethylpimelimidate (Sigma) was added to give a final concentration of $20 \mathrm{~mm}$. The beads were incubated at room temperature for $30 \mathrm{~min}$ on the rotating mixer, and the reaction was stopped by washing the beads in $0.2 \mathrm{M}$ ethanolamine $(\mathrm{pH} 8.0)$ for $2 \mathrm{hr}$ at room temperature. The beads were resuspended in PBS and stored at $4^{\circ} \mathrm{C}$. Chromatography was carried out by packing the beads into a $2-\mathrm{ml}$ syringe plugged with glass wool. The flow was controlled with a piece of silicon tubing and a regulator clip.

\section{Acknowledgments}

We are grateful to Christiane Nüsslein-Volhard for providing lodestar alleles, and to Mark Liebowitz and Jordan Raff for their initial phenotypic characterization of the mutants. Bruce Baker generously provided all of the cloned DNA from the region and several additional cDNA clones; he also communicated many unpublished results. We are grateful to Jordan Raff for the gift of the RNA used for Northern blotting and to Kevin O'Hare for providing the Northern blot of RNA from the dysgenic cross (Fig. 4C). The 0- to 4-hr embryo cDNA library was the kind gift of Nicholas Brown. The PESTFIND computer program was a gift of Martin Rechsteiner. We thank Cayetano Gonzalez, Brian Dalby, and Gabriela Maldonado-Codina for their comments on the manuscript. C.H.G. received a studentship from the Science and Engineering Research Council and postdoctoral support from the Cancer Research Campaign. This research was funded by the Cancer Research Campaign.

The publication costs of this article were defrayed in part by payment of page charges. This article must therefore be hereby marked "advertisement" in accordance with 18 USC section 1734 solely to indicate this fact.

\section{References}

Axton, J.M., V. Dombradi, P.T.W. Cohen, and D.M. Glover. 1990. One of the protein phosphatase 1 isoenzymes in Drosophila is essential for mitosis. Cell 63: 33-46.

Baker, B.S. and M.F. Wolfner. 1988. A molecular analysis of doublesex, a bifunctional gene that controls both male and female sexual differentiation in Drosophila melanogaster. Genes \& Dev. 2: 477-489.

Baker, B.S., G. Hoff, T.C. Kaufman, M. Wolfner, and T. Hazelrigg. 1991. The doublesex locus of Drosophila melanogaster and its flanking regions: A cytogenetic analysis. Genetics 127: 125-138.

Birnstiel, M.L., M. Busslinger, and K. Strub. 1985. Transcription termination and $3^{\prime}$ processing: The end is in site! Cell
41: 349-359.

Blow, J.J. and R.A. Laskey. 1988. A role for the nuclear envelope in controlling DNA replication within the cell cycle. Nature 332: $546-547$.

Brown, N.H. and F.C. Kafatos. 1988. Functional cDNA libraries from Drosophila embryos. I. Mol. Biol. 203: 425-437.

Burtis, K.C. and B.S. Baker. 1989. Drosophila doublesex gene controls somatic sexual differentiation by producing alternatively spliced mRNAs encoding related sex-specific polypeptides. Cell 56: 997-1010.

Carroll, S.B. and A. Laughon. 1987. Production and purification of polyclonal antibodies to the foreign segment of $\beta$-galactosidase fusion proteins. In DNA cloning: A practical approach (ed. D.M. Glover), vol. III, pp. 89-112. IRL Press, Oxford.

Cavener, D.R. 1987. Comparison of the consensus sequence flanking translational start sites in Drosophila and vertebrates. Nucleic Acids Res. 15: 1353-1361.

Cross, F., J. Roberts, and H. Weintraub. 1989. Simple and complex cell cycles. Annu. Rev. Cell Biol. 5: 341-395.

Dequin, R., H. Saumweber, and J.W. Sedat. 1984. Proteins shifting from the cytoplasm into the nuclei during early embryogenesis of Drosophila melanogaster. Dev. Biol. 104: 37-48.

Edgar, B.A. and P.H. O'Farrell. 1989. Genetic control of cell division patterns in the Drosophila embryo. Cell 57: 177187.

1990. The three postblastoderm cell cycles of Drosophila embryogenesis are regulated in G2 by string. Cell 62: $469-480$.

Edgar, B.A. and G. Schubiger. 1986. Parameters controlling transcriptional activation during early Drosophila development. Cell 44: 871-877.

Foe, V.E. 1989. Mitotic domains reveal early commitment of cells in Drosophila embryos. Development 107: 1-22.

Foe, V.E. and B.M. Alberts. 1983. Studies of nuclear and cytoplasmic behaviour during the five mitotic cycles that precede gastrulation in Drosophila embryogenesis. J. Cell Sci. 61: $31-70$.

Freeman, M. and D.M. Glover. 1987. The gnu mutation of Drosophila causes inappropriate DNA synthesis in unfertilized and fertilized eggs. Genes \& Dev. 1: 924-930.

Freeman, M., C. Nüsslein-Volhard, and D.M. Glover. 1986. The dissociation of nuclear and centrosomal division in $\mathrm{gnu}$, a mutation causing giant nuclei in Drosophila. Cell 46: 457468.

Garcia-Bellido, A. and J. Moscoso del Prado. 1979. Genetic analysis of maternal information in Drosophila. Nature 278: $346-348$.

Gatti, M. and B.S. Baker. 1989. Genes controlling essential cellcycle functions in Drosophila melanogaster. Genes \& Dev. 3: $438-453$.

Gatti, M., S. Pimpinelli, C. Bove, B.S. Baker, D.A. Smith, A.T.C. Carpenter, and P. Ripoll. 1983. Genetic control of mitotic cell division in Drosophila melanogaster. In Fifteenth Proceeding of the International Congress of Genetics, New Delhi. vol. 2, pp. 193-204. Oxford and IBH Publishing, New Delhi.

Gonzalez, C., J. Casal, and P. Ripoll. 1988. Functional monopolar spindles caused by mutation in $m g r$, a cell division gene of Drosophila melanogaster. J. Cell Sci. 89: 39-47.

Gonzalez, C., R.D.C. Saunders, J. Casal, I. Molina, M. Carmena, P. Ripoll, and D.M. Glover. 1990. Mutations at the asp locus of Drosophila lead to multiple free centrosomes in syncytial embryos, but restrict centrosome duplication in larval neuroblasts. J. Cell Sci. 96: 605-616.

Gorbalenya, A.E., E.V. Koonin, A.P. Donchenko, and V.M. Blinov. 1989. Two related superfamilies of putative helicases 
involved in replication, recombination, repair and expression of DNA and RNA genomes. Nucleic Acids Res. 17: 4713-4730.

Hagan, I. and M. Yanagida. 1990. Novel potential mitotic motor protein encoded by the fission yeast $\mathrm{cut}^{+}$gene. Nature 347: 563-566.

Hartwell, L.H. and T.A. Weinert. 1989. Checkpoints: Controls that ensure the order of cell cycle events. Science 246: 629634.

Hennessy, K.M., C.D. Clark, and D. Botstein. 1990. Subcellular localization of yeast $C D C 46$ varies with the cell cycle. Genes \& Dev. 4: 2252-2263.

Hirano, T., S. Funahashi, T. Uemera, and M. Yanagida. 1986. Isolation and characterization of Schizosaccharomyces pombe cut mutants that block nuclear division but not cytokinesis. EMBO /. 5: 2973-2979.

Kalderon, D., B.L. Roberts, W.D. Richardson, and A.E. Smith. 1984. A short amino acid sequence able to specify nuclear localization. Cell 39: 499-509.

Karess, R. and D.M. Glover. 1989. rough deal: A gene required for proper mitotic segregation in Drosophila. I. Cell Biol. 109: 2951-2961.

Klemenz, R., U. Weber, and W.J. Gehring. 1987. The white gene as a marker in a new P-element vector for gene transfer in Drosophila. Nucleic Acids Res. 15: 3947-3959.

Lin, H. and M.F. Wolfner. 1991. The Drosophila maternal-effect gene $f_{S}(1) \mathrm{Ya}$ encodes a cell cycle-dependent nuclear envelope component required for embryonic mitosis. Cell 64: 49-62.

Lindsley, D.L. and G. Zimm. 1985. The genome of Drosophila melanogaster. Part 1: Genes A-K. Dros. Inf. Serv. 62: 1-227.

- 1987. The genome of Drosophila melanogaster. Part 3: Rearrangements. Dros. Inf. Serv. 65: 1-224.

- 1990. The genome of Drosophila melanogaster. Part 4: Genes L-Z, balancers and transposable elements. Dros. Serv. 68: 1-382.

Marston, F.A.O. 1987. The purification of eukaryotic polypeptides expressed in Escherichia coli. In DNA cloning: A practical approach (ed. D.M. Glover), vol. III, pp. 59-88. IRL Press, Oxford.

Merrill, P.T., D. Sweeton, and E. Wieschaus. 1988. Requirements for autosomal gene activity during precellular stages of Drosophila melanogaster. Development 104: 495-503.

Mozer, B., R. Marlor, S. Parkhurst, and V. Corces. 1985. Characterization and developmental expression of Drosophila ras oncogene. Mol. Cell. Biol. 5: 885-889.

Nasmyth, K., G. Adolf, D. Lydall, and A. Seddon. 1990. The identification of a second cell cycle control on the $H O$ promoter in yeast: Cell cycle regulation of SW15 nuclear entry. Cell 62: 631-647.

O'Farrell, P.H., B.A. Edgar, D. Lakich, and C.F. Lehner. 1989. Directing cell division during development. Science 246: 635-640.

Perrimon, N., D. Mohler, L. Engstrom, and A.P. Mahowald. 1986. X-linked female sterile loci in Drosophila melanogaster. Genetics 113: 695-712.

Raff, J.W. and D.M. Glover. 1988. Nuclear and cytoplasmic cycles continue in Drosophila embryos in which DNA synthesis is inhibited with aphidicolin. J. Cell Biol. 107: 20092019.

- 1989. Centrosomes, and not nuclei, initiate pole cell formation in Drosophila embryos. Cell 57: 611-619.

Rechsteiner, M. 1988. Regulation of enzyme levels by proteolysis: The role of PEST regions. Adv. Enzyme Regul. 27: 135151.

Rihs, H.-P., D.A. Jans, H. Fan, and R. Peters. 1991. The rate of nuclear cytoplasmic protein transport is determined by the casein kinase II site flanking the nuclear localisation signal of the SV40 T-antigen. EMBO I. 10: 633-639.

Roberts, B. 1989. Nuclear location signal-mediated protein transport. Biochim. Biophys. Acta 1008: 263-280.

Rogers, S., R. Wells, and M. Rechsteiner. 1986. Amino acid sequences common to rapidly degraded protein: The PEST hypothesis. Science 234: 364-368.

Roth, S., D. Stein, and C. Nüsslein-Volhard. 1989. A gradient of nuclear localization of the dorsal protein determines the dorsoventral pattern in the Drosophila embryo. Cell 59: 11891202.

Rushlow, C.A., K. Han, J.L. Manley, and M. Levine. 1989. The graded distribution of the dorsal morphogen is initiated by selective nuclear transport in Drosophila. Cell 59: 11651177.

Ruther, U. and B. Muller-Hill. 1983. Easy identification of cDNA clones. EMBO J. 2: 1791-1794.

Sambrook, J., E.F. Fritsch, and T. Maniatis. 1989. Molecular cloning: A laboratory manual, 2nd ed. Cold Spring Harbor Laboratory Press, Cold Spring Harbor, New York.

Sanger, F., S. Nicklen, and A.R. Coulson. 1977. DNA sequencing with chain terminating inhibitors. Proc. Nat1. Acad. Sci. 74: 5463-5467.

Shearn, A., T. Rice, A. Garen, and W. Gehring. 1971. Imaginal disc abnormalities in lethal mutants of Drosophila. Proc. Natl. Acad. Sci. 68: 2594-2598.

Smith, D.A., B.S. Baker, and M. Gatti. 1985. Mutations in genes encoding essential mitotic functions in Drosophila melanogaster. Genetics 110: 647-670.

Stafstrom, J.P. and L.A. Staehelin. 1984. Dynamics of the nuclear envelope and of nuclear pore complexes during mitosis in the Drosophila embryo. Eur. J. Cell Biol. 34: 179-189.

Steward, R. 1989. Relocalization of the dorsal protein from the cytoplasm to the nucleus correlates with its function. Cell 59: 1179-1188.

Szabad, J. and P.J. Bryant. 1982. The mode of action of "Discless" mutations in Drosophila melanogaster. Dev. Biol. 93: 240-256.

Tearle, R. and C. Nüsslein-Volhard. 1987. Tübingen mutants and stocklist. Dros. Inf. Serv. 66: 209-269.

Uemura, T., H. Ohkura, Y. Adachi, K. Morino, K. Shiozaki, and M. Yanagida. 1987. DNA topoisomerase II is required for condensation and separation of mitotic chromosomes in $S$. pombe. Cell 50: 917-925.

Vessey, K.B., R.L. Ludwiczak, A.S. Briot, and E.M. Underwood. 1991. abnormal chromatin $(a b c)$, a maternal-effect locus of Drosophila melanogaster. I. Cell Sci. 98: 233-243.

Walker, J.E., M. Saraste, M.J. Runswick, and N.J. Gay. 1982. Distantly related sequences in the $\alpha$ - and $\beta$-subunits of ATP synthase, myosin, kinases and other ATP-requiring enzymes and a common nucleotide binding fold. EMBO I. 8: 945-951.

Whitfield, W.G.F., C. Gonzalez, G. Maldonado-Codina, and D.M. Glover. 1990. The A- and B-type cylins are accumulated and destroyed in temporally distinct events that define separable phases of the G2-M transition. EMBO I. 9: 25632572.

Wieschaus, E. and D. Sweeton. 1988. Requirements for X-linked zygotic gene activity during cellularization of early Drosophila embryos. Development 104: 483-493.

Zahner, J.E. and C.M. Cheney. 1990. quartet: A Drosophila developmental mutation affecting chromosome separation in mitosis. Dev. Genet. 11: 27-40.

Zhang, P., B.A. Knowles, L.S.B. Goldstein, and R.S. Hawley. 1990. A kinesin-like protein required for distributive chromosome segregation in Drosophila. Cell 62: 1053-1062. 


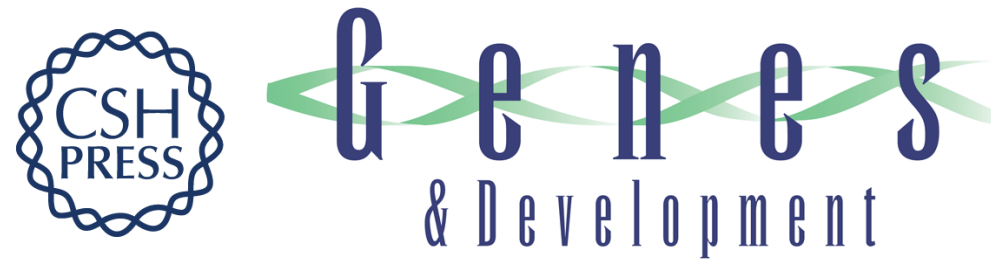

\section{Chromosome tangling and breakage at anaphase result from mutations in lodestar, a Drosophila gene encoding a putative nucleoside triphosphate-binding protein.}

C H Girdham and D M Glover

Genes Dev. 1991, 5:

Access the most recent version at doi:10.1101/gad.5.10.1786

References This article cites 61 articles, 22 of which can be accessed free at:

http://genesdev.cshlp.org/content/5/10/1786.full.html\#ref-list-1

License

Email Alerting Service

Receive free email alerts when new articles cite this article - sign up in the box at the top right corner of the article or click here.

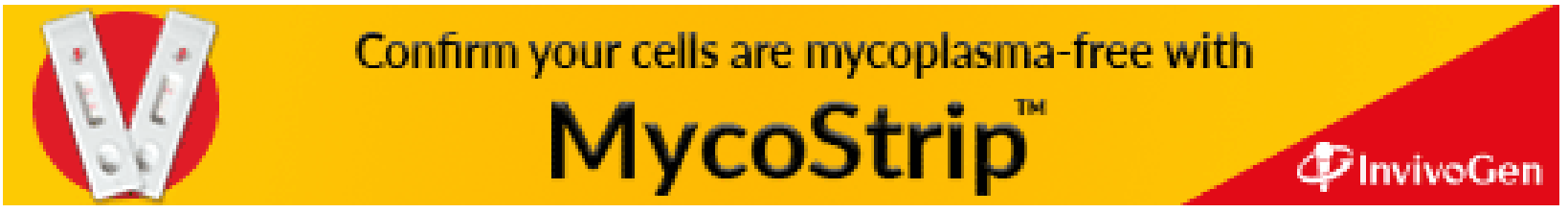

